Final Technical Report

(August 10, 1995 - June 30, 1999)

\title{
AN ADVANCED CONTROL SYSTEM FOR FINE COAL FLOTATION
}

\author{
Principal Investigators \\ G.T. Adel and G. H. Luttrell \\ Department of Mining and Minerals Engineering \\ Virginia Polytechnic Institute and State University \\ Blacksburg, Virginia 24061
}

Contract Number

DE-AC22-95PC95150--13

DOE Project Officer

Carl Maronde

United States Department of Energy

Federal Energy Technology Center

P. O. Box 10940

Pittsburgh, Pennsylvania 15236-0940

Draft: June 7, 1999

Final: December 20, 1999

"US/DOE patent clearance is not required prior to the publication of this document." 


\begin{abstract}
A model-based flotation control scheme has been implemented to achieve optimal performance in the handling and treatment of fine coal. The control scheme monitors flotation performance through on-line analysis of tailings ash content. Then, based on an on-line estimate of incremental ash, the pulp level is adjusted using a model-based control algorithm to compensate for feed variations and other process disturbances. A novel, video-based optical analyzer has been employed for on-line determination of slurry ash content.

Based on the results of this test work, the following major conclusions can be drawn:

1. The video-based ash analyzer is a technically feasible and economic alternative for on-line ash analysis of tailings slurries containing in excess of $65 \%$ ash. Its accuracy is comparable to that of nuclear based analyzers, and it is nearly an order of magnitude less expensive.

2. A model-based estimator (i.e., soft sensor) can be used to effectively calculate the ash content of the last increment of coal recovered from a flotation bank (i.e., incremental ash).

3. The model-based control strategy employed here is capable of moving the plant to a given (feasible) target and keeping it there.

4. For any given incremental ash target, the model-based control strategy reduces the sum-ofsquares of deviations from the target by a factor of six compared with current plant operation.
\end{abstract}




\section{TABLE OF CONTENTS}

\section{page}

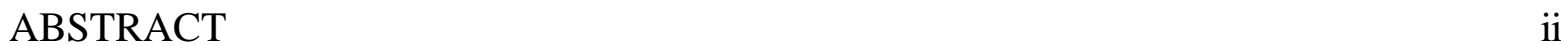

TABLE OF CONTENTS $\quad$ iii

LIST OF ILLUSTRATIONS, TABLES AND FIGURES iv

EXECUTIVE SUMMARY vi

$\begin{array}{ll}\text { INTRODUCTION } & 1\end{array}$

TECHNICAL DISCUSSION 2

Sampling and Data Analysis $\quad 2$

Baseline Plant Audit 3

Residence Time Distribution Test $\quad 7$

$\begin{array}{lr}\text { Disturbance Testing } & 8\end{array}$

Model Building and Computer Simulation 12

Model Format 12

Model Simplification $\quad 15$

Simulator Development $\quad 18$

Control Strategy Selection and Evaluation $\quad 19$

Expert Supervisory System Development 24

Sensor Testing $\quad 26$

Analyzer Description $\quad 26$

$\begin{array}{ll}\text { Analyzer Calibration } & 28\end{array}$

Operation and Testing $\quad 30$

System Start-Up and Shakedown Testing $\quad 30$

Data Collection and Control Strategy Evaluation 34

$\begin{array}{ll}\text { System Evaluation } & 39\end{array}$

$\begin{array}{ll}\text { CONCLUSIONS } & 41\end{array}$

$\begin{array}{ll}\text { REFERENCES } & 43\end{array}$

$\begin{array}{ll}\text { NOMENCLATURE } & 44\end{array}$

APPENDIX A - Material Balance Procedure 48

APPENDIX B - Raw Data from Audit of Pittston's Moss No. 3 Flotation Circuit 53

APPENDIX C - Video Sensor Calibration Data 60 


\section{LIST OF ILLUSTRATIONS, TABLES AND FIGURES}

page

Figure 1. Schematic diagram of Pittston's Moss No. 3 flotation circuit. 2

Figure 2. Transient and steady-state samples collected during factorial testing. $\quad 4$

Figure 3. Factorial test series ash content results. $\quad 5$

Figure 4. Factorial test series yield and combustible recovery results. 5

Figure 5. Transient response in \% ash to changes in manipulated variables. 6

$\begin{array}{lll}\text { Figure 6. } & \text { Experimental and fitted residence time distributions. } & 8\end{array}$

$\begin{array}{ll}\text { Figure 7. Dynamic variation tests. } & 9\end{array}$

Figure 8. Release analysis tests performed on the dynamic variation samples. 10

Figure 9. Schematic of the four possible states of particles in a flotation cell. 12

Figure 10. Multisize model fit compared with experimental values. 15

Figure 11. Entrainment and flotation rate contributions to total rate. 15

Figure 12. Particle composition distribution for the feed sample from factorial test $2 . \quad 17$

Figure 13. Conceptual design of incremental ash control system. 21

Figure 14. Sensitivity of incremental ash to changes in manipulated variables. 22

Figure 15. Yield and clean coal ash dependence on pulp level. 23

Figure 16. Incremental ash dependence on pulp level. 23

Figure 17. Influence of amenability ratio on tails ash. 24

$\begin{array}{ll}\text { Figure 18. Expert system logic. } & 25\end{array}$

Figure 19. Schematic diagram of the video-based ash analyzer. 27

Figure 20. Overall schematic diagram of the video-based ash analyzer. 28

Figure 21. Calibration plot for the video-based ash analyzer showing data points obtained from April through September, 1998. 
Figure 22. Interfacing the supervisory PC to the flotation circuit and control system.

Figure 23. Main screen of the control program.

Figure 24. Plant test of controllability of incremental ash at Moss \#3.

Figure 25. Standard plant operation baseline.

Figure 26. Short term on-off testing of control system performance.

Figure 27. Long term control strategy performance at Pittston's Moss \#3.

Figure A1. Flotation cell showing the variables used for the mass balance.

Table 1. Factorial Design Test Summary

Table 2. Supervisory PC I/O to Flotation Circuit and Control System

Table 3. Summary of Expert System Operator Interface

Table 4. Analysis of Incremental Ash Data During On-Off Testing 


\section{EXECUTIVE SUMMARY}

Over the past thirty years, process control has spread from the chemical industry into the fields of mineral and coal processing. Today, process control computers, combined with improved instrumentation, are capable of effective control in many modern flotation circuits. Unfortunately, the classical methods used in most control strategies have severe limitations when used in froth flotation. For example, the nonlinear nature of the flotation process can cause single-input, single-output lines to battle each other in attempts to achieve a given objective. Other problems experienced in classical control schemes include noisy signals from sensors and the inability to measure certain process variables. Factors related to ore type or water chemistry, such as liberation, froth stability, and floatability, are often difficult or impossible to measure.

The purpose of this project was to demonstrate an advanced control system for fine coal flotation. The demonstration was carried out at an existing coal preparation plant by a team consisting of Virginia Polytechnic Institute and State University (VPI\&SU) as the prime contractor and J.A. Herbst and Associates as a subcontractor. The objectives of this work were: 1) to identify through sampling, analysis, and simulation those variables which can be manipulated to maintain grades, recoveries, and throughput rates at levels set by management; 2) to develop and implement a model-based control strategy that continuously adjusts those variables to maximize revenue subject to various metallurgical, economic, and environmental constraints; and 3) to employ a video-based analyzer for on-line analysis of ash content in fine coal slurries.

The work was carried out at the Moss No. 3 preparation plant owned and operated by Pittston Coal Company. Initially, a sampling campaign was conducted around the flotation bank at the Moss No. 3 plant to obtain data for model building and dynamic analysis. A detailed 
population balance model was then constructed and used to test various control schemes. Based on these tests and discussions with plant personnel, a control scheme was developed to maintain a constant incremental ash (i.e., the ash content of the last increment of coal recovered) in the flotation bank. A target incremental ash value of $38 \%$ was initially selected based on the specific gravity cut points used in the coarse coal circuits; however, this value was later reduced to $27 \%$ due to physical constraints imposed by the plant filtration capacity. In the mean time, a videobased ash analyzer, developed by the PI's under a previous DOE grant (DE-FG22-94PC94226), was installed and calibrated for on-line analysis of the flotation tailings stream. The output from this analyzer was used in conjunction with the flotation model to provide an estimate of the incremental ash from the flotation bank. The estimate from this "soft sensor" became the basis for making adjustment to pulp level in order to maintain the target incremental ash.

As a result of the work performed under this contract, the following conclusions can be made:

1. The video-based ash analyzer is a technically feasible and economic alternative for on-line ash analysis of tailings slurries containing in excess of $65 \%$ ash. Its accuracy is comparable to that of nuclear based analyzers, and it is nearly an order of magnitude less expensive.

2. A model-based estimator (i.e., soft sensor) can be used to effectively calculate the ash content of the last increment of coal recovered from a flotation bank (i.e., incremental ash).

3. The model-based control strategy employed here is capable of moving the plant to a given (feasible) target and keeping it there.

4. For any given incremental ash target, the model-based control strategy reduces the sum-ofsquares of deviations from the target by a factor of six compared with current plant operation. 


\section{INTRODUCTION}

Over the past thirty years, process control has spread from the chemical industry into the fields of mineral and coal processing. Today, process control computers, combined with improved instrumentation for monitoring process parameters and performance, have demonstrated improved control in many modern flotation plants. Unfortunately, the classical methods used in most control strategies have severe limitations when it comes to control of froth flotation. The nonlinear nature of the flotation process, for example, can cause single-input, single-output control lines to battle each other in attempts to achieve a specific control objective. Other problems experienced in classical control schemes include noisy signals from measuring devices and the inability to measure certain process variables. Furthermore, factors related to ore type or process water chemistry, such as liberation characteristics, froth stability, and floatability, cannot be measured by conventional means.

The purpose of this project is to demonstrate an advanced control system for fine coal flotation at an operating coal preparation plant. The objectives of this work are: 1) to identify through sampling, analysis, and simulation those variables which can be manipulated in the plant to maintain grades, recoveries, and throughput rates at levels set by management; 2) to develop and implement a model-based computer control strategy that continuously adjusts those variables to maximize revenue subject to various metallurgical, economic, and environmental constraints; and 3) to employ a video-based optical analyzer for on-line analysis of ash content in fine coal slurries. 


\section{TECHNICAL DISCUSSION}

\section{Sampling and Data Analysis}

During the latter part of November, 1997, a plant sampling campaign was conducted at the Moss No. 3 preparation plant owned and operated by Pittston Coal Company. The purpose of this sampling campaign was to characterize the dynamic and steady-state performance of the flotation bank in preparation for modeling and process control activities. This bank treats approximately 100 tph of -100 mesh coal to produce both steam and metallurgical grade products.

A schematic diagram of the flotation bank at the Moss No. 3 plant is shown in Figure 1. As shown, the bank consists of four 1000-cubic-foot Wemco cells operating at a feed flow rate of approximately $8000 \mathrm{gpm}$. Feed to the cells comes from classifying cyclone overflow. The only on-line instrumentation in place at the start of this project was a dart valve in the tailings box for control of pulp level. An automatic sampling system on the feed, clean coal, and tailings streams provides a consistent set of samples for periodic analysis at the on-site laboratory.

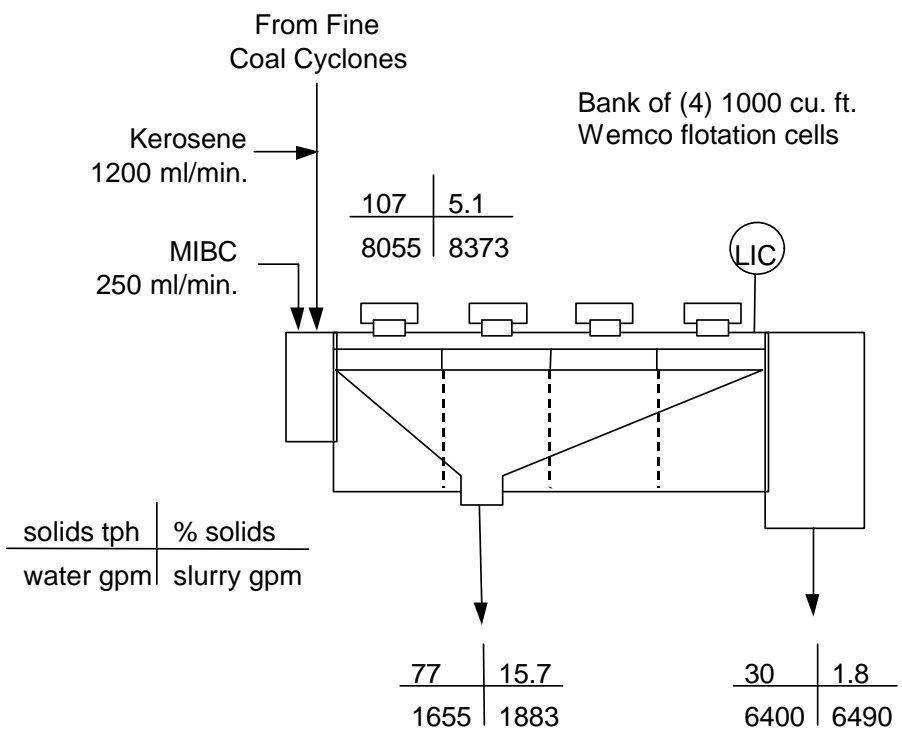

Figure 1. Schematic diagram of Pittston's Moss No. 3 flotation circuit. 
The sampling campaign consisted of three types of tests including:

1. a $2^{3}$ factorial design to determine the effects of collector, frother, and pulp level on the performance of the flotation bank and to estimate the parameters for the flotation model (The design was blocked into two, half-factorial designs, one at low feed rate and the other at high feed rate.),

2. a residence time distribution test using a lithium chloride tracer, and

3. a series of batch flotation tests using flotation feed samples to determine variability in the floatability of the coal.

Baseline Plant Audit: A schematic of the $2^{3}$ factorial design is shown in Table 1 . As shown, each variable in the test takes on two values, -1 and +1 , representing high and low levels. This results in four possible combinations plus a center point for each feed rate, producing a total of ten tests. The sequence of tests was randomized within each feed rate block. To compare the response of the dynamic flotation model and the plant, transient samples were collected for each test between the time the change in variables was made and the final steady-state was reached. As shown in Figure 2, the change in manipulated variables was made at time $t=0$, and three transient samples were collected at 3,6, and 12 minutes. The last sample at 20 minutes was considered to be the steady-state sample. Pulp level was varied using the dart valve controller in the tailings box. Reagent additions were adjusted at the reagent feeders. Since there was no good way to adjust feed rate, the plant superintendent agreed to reduce overall plant feed by 100 tph for half of a shift. The samples obtained from the plant audit were analyzed for percent ash, percent solids, particle size distribution, and particle composition. These assays were all material balanced (see Appendix A) prior to subsequent use in constructing the flotation model. 
Table 1. Factorial Design Test Summary

\begin{tabular}{|c||c|c|c|c||}
\hline Test & Frother & Level & Collector & Feed Rate \\
\hline \hline 1 & $\mathbf{- 1}(0.08 \mathrm{lb} /$ ton $)$ & $\mathbf{1}$ & $\mathbf{- 1}(0.8 \mathrm{lb} /$ ton $)$ & $\mathbf{+ 1}(1000 \mathrm{tph})$ \\
\hline 2 & $\mathbf{1}(0.12 \mathrm{lb} /$ ton $)$ & $\mathbf{1}(67$ inches $)$ & $\mathbf{1}(1.2 \mathrm{lb} /$ ton $)$ & $\mathbf{+ 1}$ \\
\hline 3 & $\mathbf{0}(0.1 \mathrm{lb} /$ ton $)$ & $\mathbf{0}(64$ inches $)$ & $\mathbf{0}(1.0 \mathrm{lb} /$ ton $)$ & $\mathbf{+ 1}$ \\
\hline 4 & $\mathbf{- 1}$ & $\mathbf{- 1}(61$ inches $)$ & $\mathbf{1}$ & $\mathbf{+ 1}$ \\
\hline 5 & $\mathbf{1}$ & $\mathbf{1}$ & $\mathbf{- 1}$ & $\mathbf{+ 1}$ \\
\hline 6 & $\mathbf{1}$ & $\mathbf{1}$ & $\mathbf{1}$ & $\mathbf{- 1}(850 \mathrm{tph})$ \\
\hline 7 & $\mathbf{- 1}$ & $\mathbf{- 1}$ & $\mathbf{1}$ & $\mathbf{- 1}$ \\
\hline 8 & $\mathbf{0}$ & $\mathbf{0}$ & $\mathbf{0}$ & $\mathbf{- 1}$ \\
\hline 9 & $\mathbf{1}$ & $\mathbf{1}$ & $\mathbf{- 1}$ & $\mathbf{- 1}$ \\
\hline 10 & $\mathbf{- 1}$ & $\mathbf{1}$ & $\mathbf{- 1}$ & $\mathbf{- 1}$ \\
\hline \hline
\end{tabular}

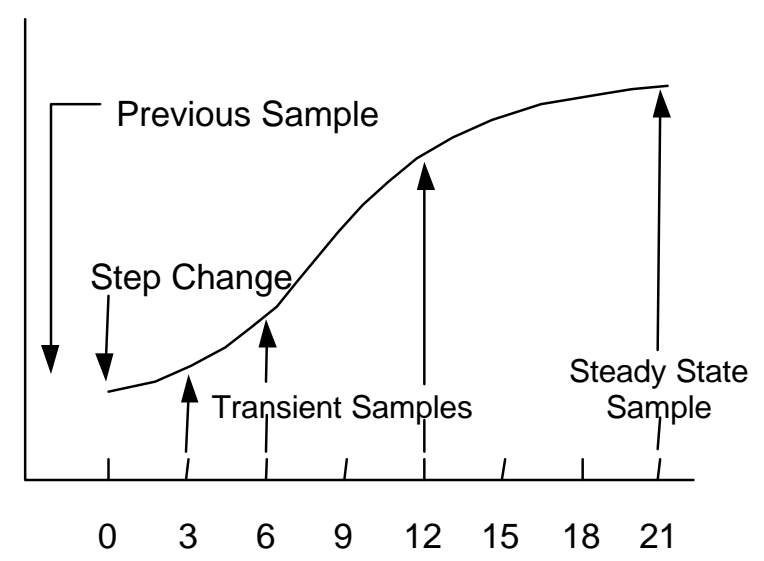

Figure 2. Transient and steady-state samples collected during factorial testing.

The steady-state, material balanced results obtained from the factorial test program are shown in Figures 3 and 4. The most striking feature of these bar charts is the lack of variation in the operation of the flotation bank in spite of the changes made during the test. Clean coal ash content varied from $8-12 \%$, while combustible recovery varied from $91-94 \%$. In fact, the biggest change in the performance of the flotation bank appears to be a result of the change in feed rate and an uncontrolled change in coal type. As it turns out, tests 1-4 were performed on the first day of the sampling campaign, and tests 5-10 were performed on the second day. During that time, it appears that the coal may have changed as evidenced by the higher ash 
content of the feed material. As shown, the feed ash for tests 6-10 is in excess of 30\%, while the feed ash for tests $1-4$ is below $30 \%$. Test 5 , which was performed on the second day of testing, may not be reliable since it appears to have been collected while the plant was still undergoing start-up disturbances. Furthermore, the slightly higher recoveries observed for tests 5-10 as compared to tests 1-4 are likely due to the reduction in feed rate. A decrease in feed rate will generally increase retention time resulting in higher recovery at the expense of product grade.

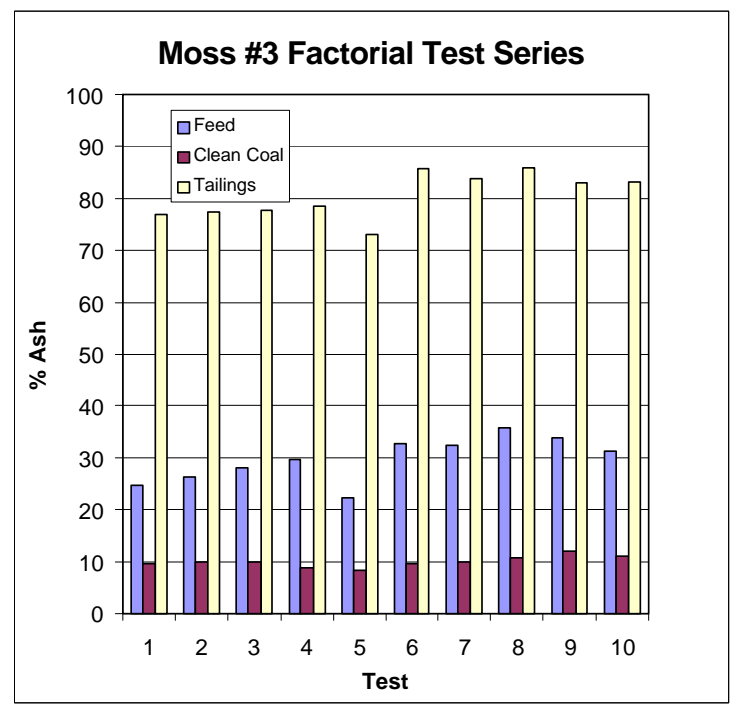

Figure 3. Factorial test series ash content results.

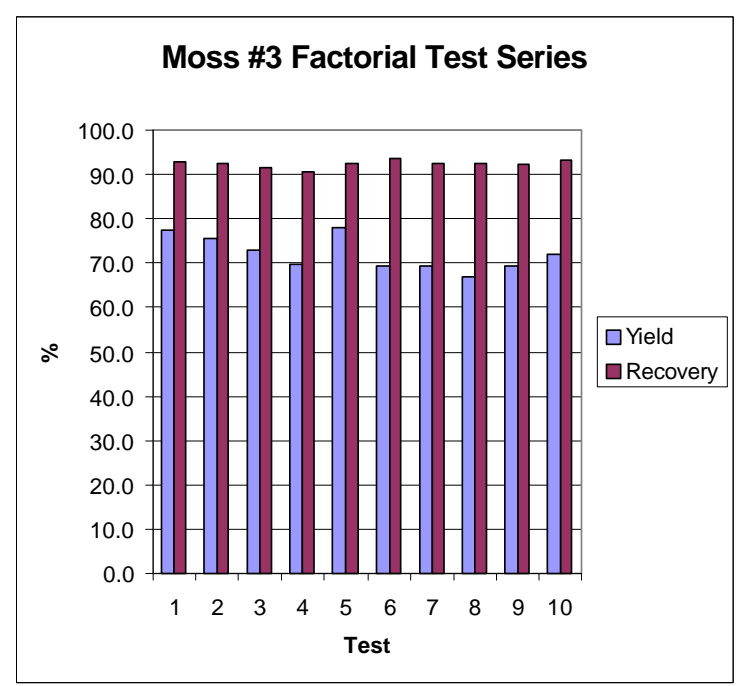

Figure 4. Factorial test series yield and combustible recovery results. 
The transient behavior of the flotation bank is illustrated in Figure 5 which shows the response of ash in the concentrate to changes in the manipulated variables at the beginning of each test (see Figure 2). In Figure 5 changes are made at time 0 minutes, 20 minutes, and so on. The sample taken 20 minutes after a change is made is the sample used for estimation of model parameters in model building. In order for a dynamic model of this process to be accurate, the response of the dynamic simulator to changes in manipulated variables must be similar to that shown in Figure 5. For almost every test an inverse response is seen immediately after a change is made. Thus, these results provide a good test for the dynamic simulator.

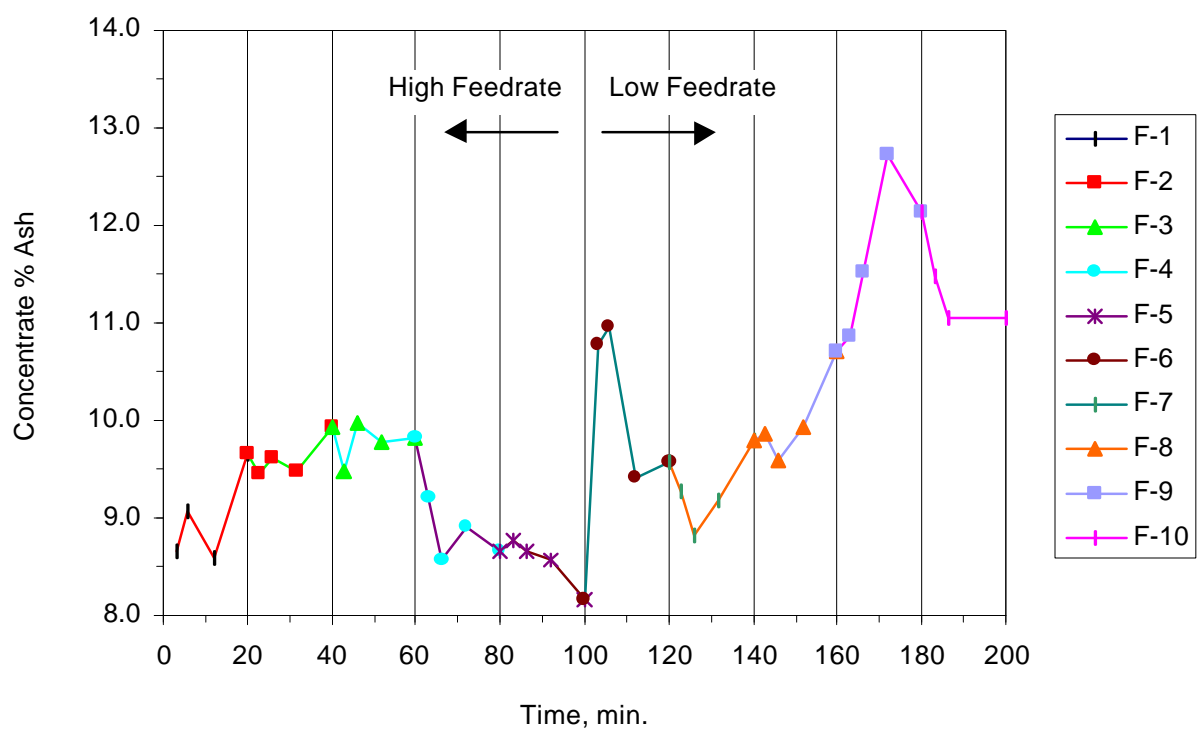

Figure 5. Transient response in \% ash to changes in manipulated variables.

In summary, the flotation bank at the Moss No. 3 plant was found to operate quite well under manual control. In spite of variations made to operating parameters, all combustible recoveries were determined to be in excess of $90 \%$. However, time-dependent fluctuations in circuit performance as a result of feed disturbances provided sufficient incentive to warrant continued work on an advanced control system. Thus, the main goal of the advanced control system in this application was to minimize variations in product quality by compensating for uncontrolled disturbances in the flotation feed. 
Residence Time Distribution Test: The residence time distribution of a reaction vessel is necessary in order to properly represent particle transport behavior in a mathematical model. It has been shown that the impulse response of an N-mixers-in-series vessel is given by:

$\frac{C(t)}{C(0)}=\frac{N^{N}(t / \tau)^{N-1}}{\tau \Gamma(N)} e^{-N(t / \tau)}$

Where $\mathrm{C}(\mathrm{t})$ is the concentration of tracer at the exit of the vessel, $\mathrm{C}(0)$ is the concentration of tracer in the vessel at time $0, \mathrm{~N}$ is the number of mixers in series, and $\tau$ is the mean residence time of the vessel.

The residence time distribution test was performed using a lithium chloride $(\mathrm{LiCl})$ tracer. One kilogram of $\mathrm{LiCl}$ was dissolved in 4 liters of water and injected into the flotation feed as a pulse at time 0 . A series of samples were then collected from the tailings box at 30 -second intervals using $500 \mathrm{ml}$ sample bottles. The liquid in the sample bottles was then decanted and analyzed for lithium concentration using atomic absorption.

Figure 6 shows the Li concentration response from the $1 \mathrm{~kg}$ impulse. In addition to the experimental data, two curves are shown. The solid line represents the best model fit to the data, while the dashed line represents the theoretical residence time distribution if each cell is represented by a single perfect mixer. As shown, the four-cell bank at the Moss No. 3 plant is very nearly represented by an ideal 4-mixers-in-series model with a mean residence time of 4 minutes. This means that the simulator can represent each cell in the bank as a single perfect mixer to adequately describe the transport behavior. 


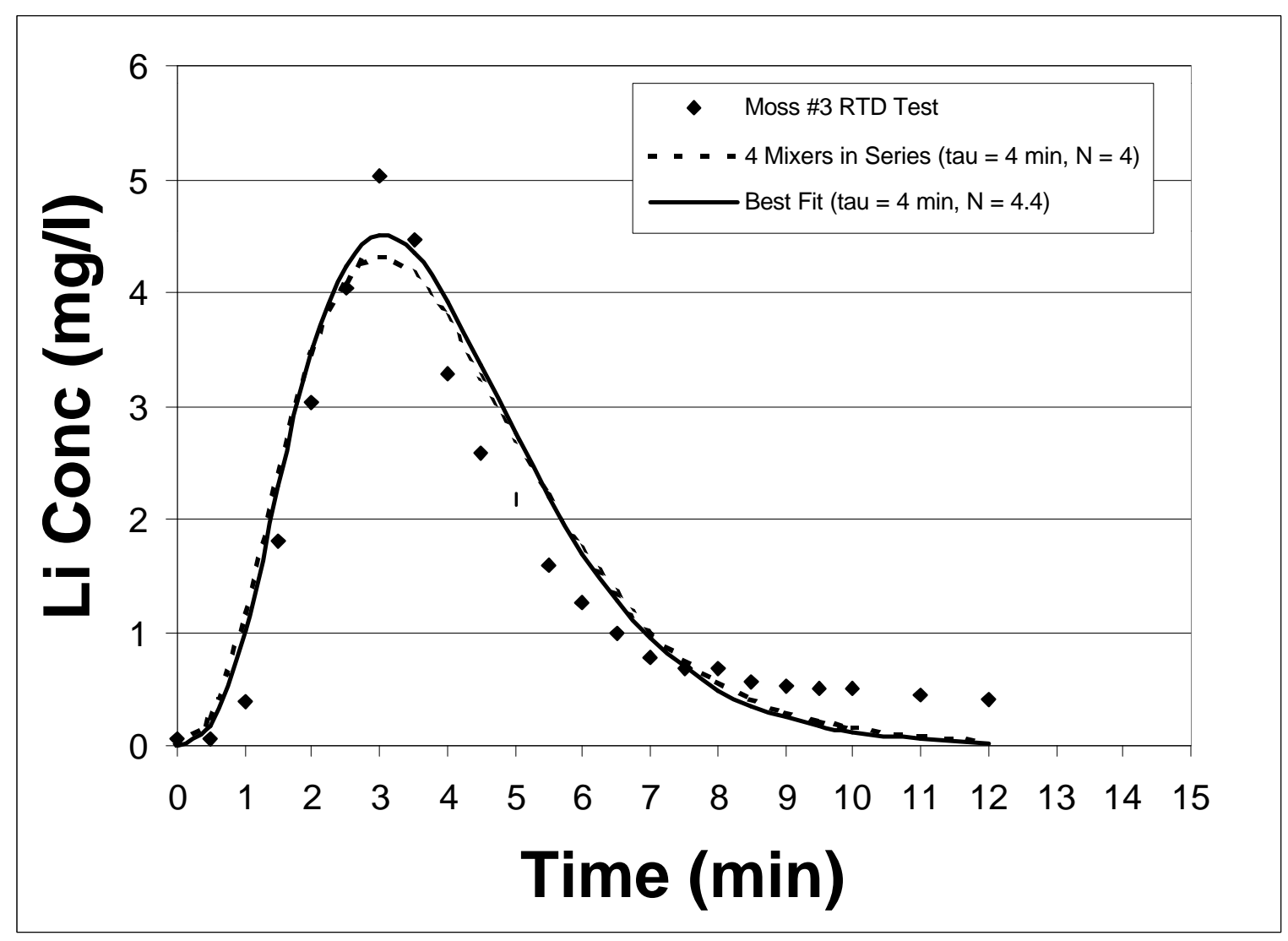

Figure 6. Experimental and fitted residence time distributions.

Disturbance Testing: Variations in coal floatability were characterized using batch flotation tests conducted on feed samples collected at progressively longer intervals between sample times. Initially samples were collected frequently to catch rapid variations. The sample times were then increased in a geometric progression to catch less frequent variations. This technique is less precise than collecting samples for short, equally spaced times, but it greatly reduces the number of samples, and it can catch both short- and long-term disturbances.

As each sample was collected, it was immediately brought to the batch flotation cell so that the chemistry of the batch flotation matched that of the actual plant as closely as possible. The sample was floated in the batch cell for 2 minutes and all froth collected during that time. The froth and tails were then filtered and analyzed for ash content. 
The results of the dynamic variation tests are shown in Figure 7. As shown, several high frequency variations appear to occur during the first half hour of the test. This is particularly evident in the tailings ash content and the combustible recovery. Although there are some variations in the feed and clean coal ash values, these do not seem to be nearly as pronounced as in the tailings ash. There also seems to be a long-term variation that occurs somewhere between the 128 minute sample and the 256 minute sample as evidenced by the change in feed ash content from below $30 \%$ to above $30 \%$. The initial high frequency variations are rather perplexing since this would normally be attributed to changes in the floatability of the feed material. However, it seems highly unlikely that coal floatability would change from high to low in a matter of 5 or 10 minutes.

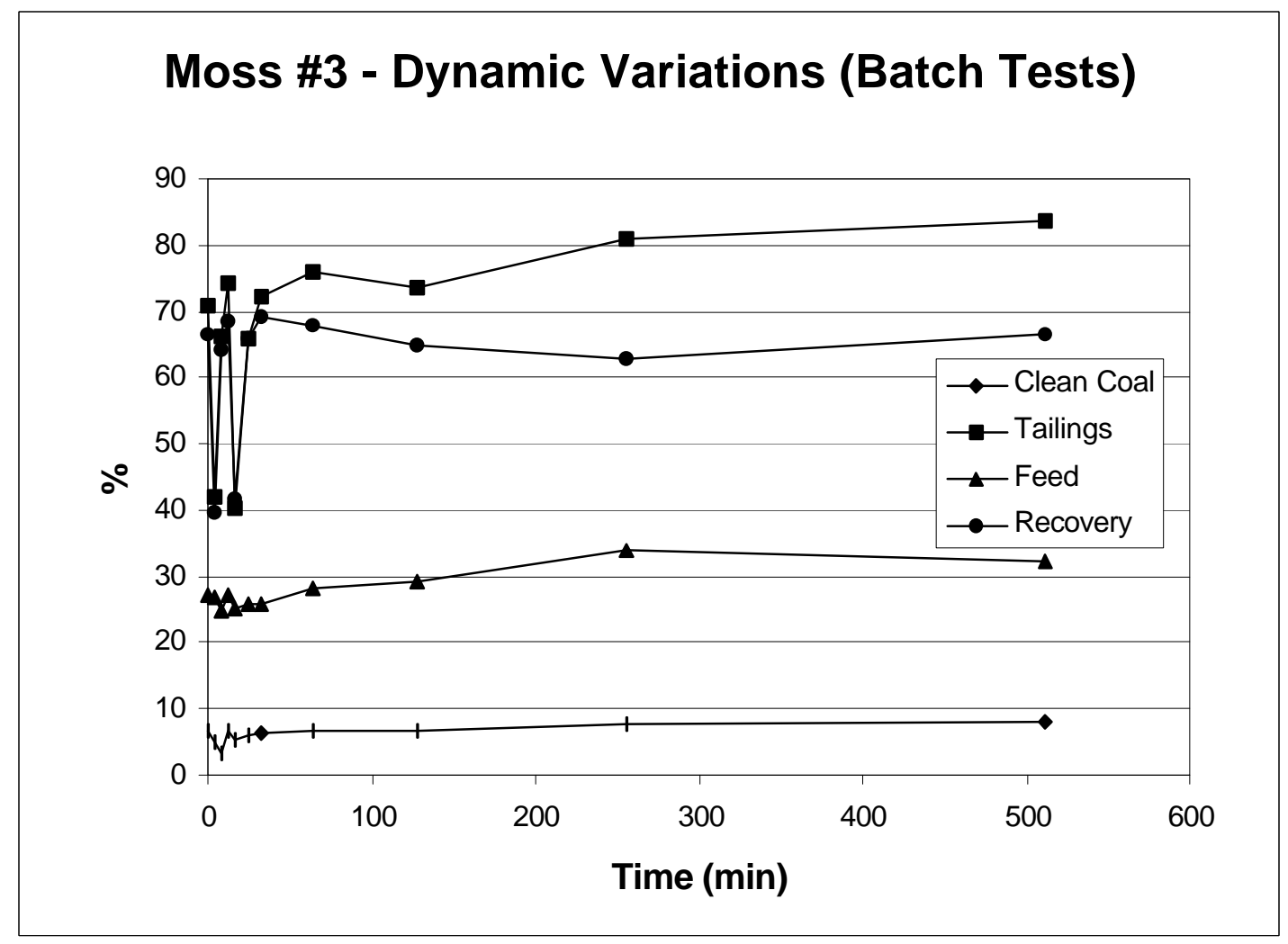

Figure 7. Dynamic variation tests. 
In order to shed further light on this matter, a series of release analysis tests were conducted in parallel with the dynamic variation tests using the same feed material. Release analysis is commonly used as a means of characterizing the floatability of a coal sample. Figure 8 shows the release analysis results obtained from this work. Because of the lengthy nature of the release procedure, it was not possible to perform release analysis on every sample. However, it can be seen that the combustible recovery vs. ash rejection curves indicate the presence of two coal types. The samples collected at 12, 24, 64 and 128 minutes all appear to follow the same characteristic curve, while the sample collected at 256 minutes indicates a coal type that is somewhat more liberated and easier to separate. This result also seems to agree with information provided by the plant superintendent regarding the types of coals being processed during the sampling campaign. Thus, the release analysis results seem to confirm the dynamic variation results in terms of the long-term variations in coal type. However, they do not appear to support the presence of short-term, high frequency variations in coal type. It is possible that the shortterm variations are due to other factors not associated with changes in feed characteristics.

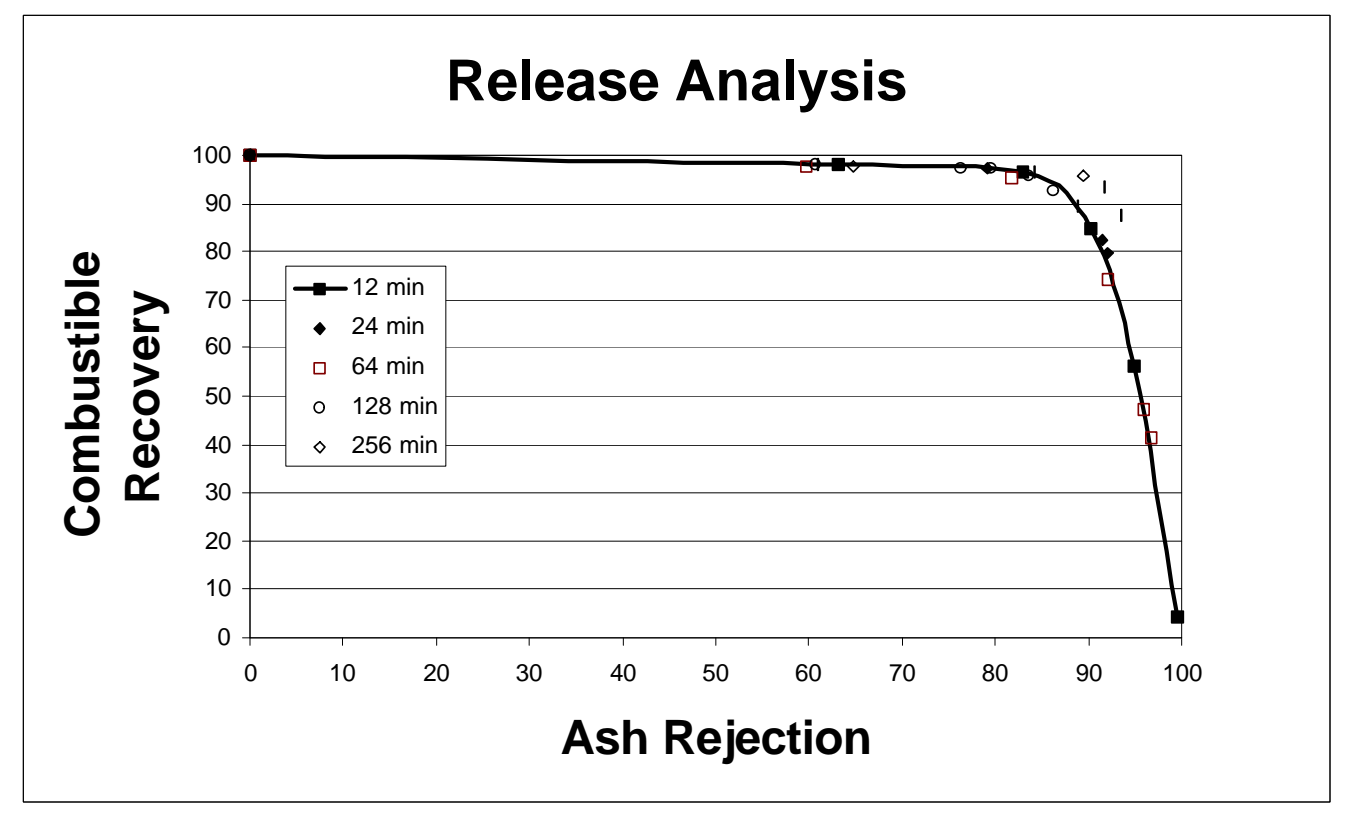

Figure 8. Release analysis tests performed on the dynamic variation samples. 
In summary, the sampling campaign conducted around the Moss No. 3 flotation bank yields the following major conclusions:

1. The flotation bank is operated quite well under manual control with combustible recoveries in excess of $90 \%$ and product ash content ranging from $8-12 \%$ in spite of variations made to operating parameters. Benefits from advanced control are most likely limited to reducing fluctuations in product quality due to uncontrolled feed disturbances.

2. Long-term feed disturbances appear to be associated with changes in coal type due to the various coal seams being processed at the Moss No. 3 plant. These disturbance generally occur on the order of 2-3 hours. Short term disturbances observed during batch flotation testing are either artifacts of the test procedure, or are associated with changes in solution chemistry which are not detectable by release analysis.

3. Residence time testing around the flotation bank indicates that, for modeling purposes, each cell in the bank can be reasonably represented as a perfect mixer.

For details on all data collected during this sampling campaign, the reader is directed to Appendix B. 


\section{Model Building and Computer Simulation}

Model Format: The most comprehensive phenomenological model that has been presented for the froth flotation process to date is the four state population balance model developed by Mika and Fuerstenau (1969). This model is depicted schematically in Figure 9.

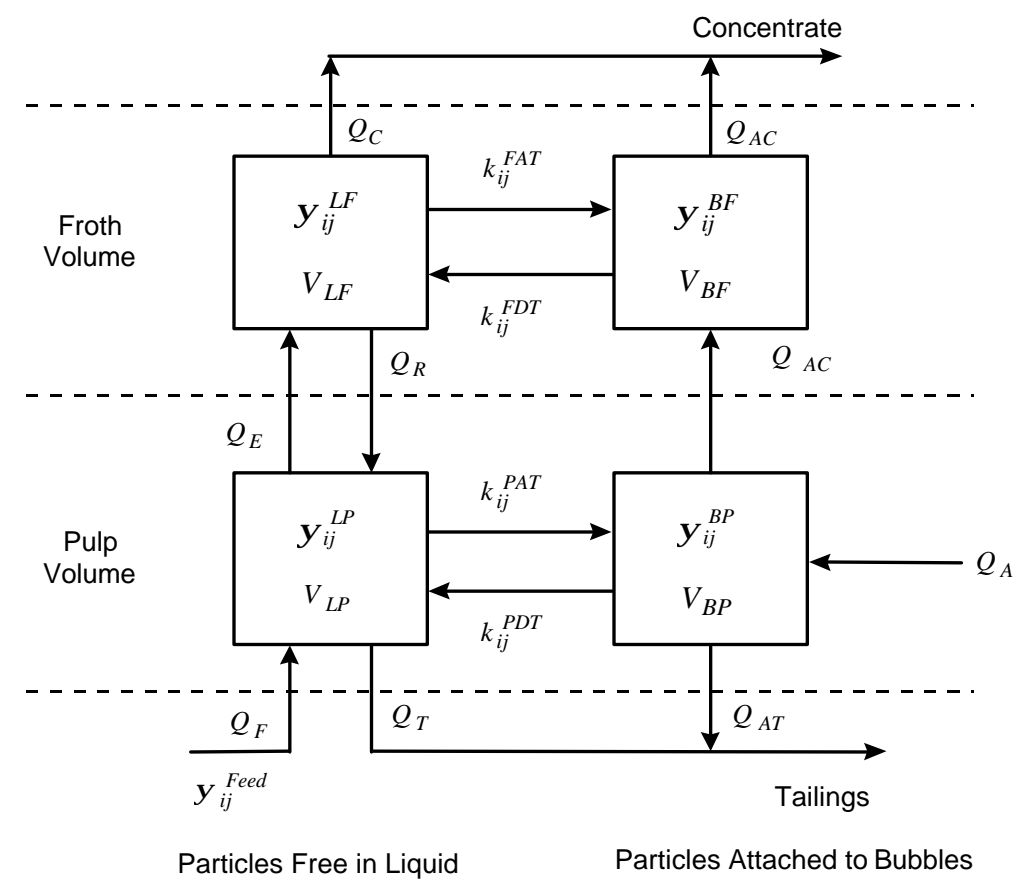

Figure 9. Schematic of the four possible states of particles in a flotation cell.

In this figure, particles of size $i$ and composition $j$ exist in four possible states: 1) free in the pulp, 2) attached to bubbles in the pulp, 3) free in the froth, and 4) attached to bubbles in the froth. The number of particles of size $i$ and composition $j$ per unit volume in any of the four states is denoted by $\psi_{i j}$. The transfer between states can be represented by rates (attachment, detachment, entrainment, drainage) which can be related to cell design and manipulated variables (Bascur and Herbst, 1982).

The resulting number balances for each particle size and composition can be obtained from the generalized conservation expression given by Equation 2:

accumulation $=$ input - output + generation 
In this balance, input and output terms represent changes in the number of particles in the specified property interval resulting from convective flow, while the generation term accounts for particles entering and leaving the specified property interval as a result of individual kinetics. The macroscopic form of the population balance model is applicable when the vessel is well mixed or when residence time distribution information is available. Thus, the overall number balances in each of the four states are given by:

Free in the pulp:

$$
\frac{d}{d t}\left(V_{L P} \psi_{i j}^{L P}\right)=Q_{F e e d} \psi_{i j}^{F e e d}+Q_{R} k_{i j}^{R} \psi_{i j}^{L F}-Q_{T} \psi_{i j}^{L P}-Q_{E} \psi_{i j}^{L P}-k_{i j}^{P A T} V_{L P} \psi_{i j}^{L P}+k_{i j}^{P D T} V_{B P} \psi_{i j}^{B P}
$$

Attached in the pulp:

$$
\frac{d}{d t}\left(V_{B P} \psi_{i j}^{B P}\right)=-Q_{A C} \psi_{i j}^{B P}-Q_{A T} \psi_{i j}^{B P}-k_{i j}^{P D T} V_{B P} \psi_{i j}^{B P}+k_{i j}^{P A T} V_{L P} \psi_{i j}^{L P}
$$

Free in the froth:

$$
\frac{d}{d t}\left(V_{L F} \psi_{i j}^{L F}\right)=Q_{E} \psi_{i j}^{L P}-Q_{C} \psi_{i j}^{L F}-Q_{R} k_{i j}^{R} \psi_{i j}^{L F}-k_{i j}^{F A T} V_{L F} \psi_{i j}^{L F}+k_{i j}^{F D T} V_{B F} \psi_{i j}^{B F}
$$

Attached in the froth:

$$
\frac{d}{d t}\left(V_{B F} \psi_{i j}^{B F}\right)=Q_{A C} \psi_{i j}^{B P}-Q_{A C} \psi_{i j}^{B F}-k_{i j}^{F D T} V_{B F} \psi_{i j}^{B F}+k_{i j}^{F A T} V_{L F} \psi_{i j}^{L F}
$$

where $\psi_{i j}^{L P}$ is the number of particles free in the liquid in the pulp per unit volume of liquid in the pulp, $\psi_{i j}^{B P}$ is the number of particles attached to bubbles in the pulp per unit volume of air in the pulp, $\psi_{i j}^{L F}$ is the number of particles free in the liquid in the froth per unit volume of liquid in the froth, $\psi_{i j}^{B F}$ is the number of particles attached to bubbles in the froth per unit volume of air in the froth, and $\psi_{i j}^{\text {Feed }}$ is the number of particles in the feed per unit volume of liquid in the feed. The interphase transfer rates are dependent on particle properties and the chemical and 
physical environment of the flotation cell where $k_{i j}^{P A T}$ is the particle attachment rate constant in the pulp, $k_{i j}^{P D T}$ is the particle detachment rate constant in the pulp, $k_{i j}^{F A T}$ is the particle attachment rate constant in the froth and $k_{i j}^{F D T}$ is the particle detachment rate constant in the froth. The input flows for particles existing as free in the pulp consist of: 1) the flow rate of feed particles into the flotation cell, $Q_{\text {Feed }} \psi_{i j}^{\text {Feed }}$, where $Q_{\text {Feed }}$ is the liquid volumetric flowrate, and 2) the return flow rate of particles draining from the froth carried by the water, $Q_{R} k_{i j}^{R} \Psi_{i j}^{L F}$, where $Q_{R}$ is the volumetric flowrate of water draining from the froth and $k_{i j}^{R}$ is a dimensionless classification constant representing the segregation that occurs in the draining liquid in the froth. The output flows for these same type of particles are: 1) the flowrate of particles leaving through the tailings port, $Q_{T} \psi_{i j}^{L P}$, where $Q_{T}$ is volumetric flowrate of liquid in the tails, and 2) the flowrate of particles entrained by the water flow, $Q_{E} \psi_{i j}^{L P}$, where $Q_{E}$ is the volumetric flowrate of water to the froth transported in the bubble film and wake. A similar analysis of transport terms can be carried out for particles that exist free in the froth, attached in the pulp, and attached in the froth. Complete definitions of all terms used in this model can be found in the Nomenclature section of this report.

Using the results obtained from the plant audit, the Mika and Fuerstenau model was fit to the steady-state data for all experimental design points. A plot of the fitted versus experimental rate constants obtained for various size fractions of clean coal is shown in Figure 10. Also shown is the estimated contribution of flotation and entrainment to the overall rate of clean coal flotation for each size fraction (Figure 11). Experimentally, entrainment can be calculated by determining the recovery of water from the flotation bank. If it is assumed that the entrained 
water has the same composition of solids as the pulp in the bank (a valid assumption for a wellmixed system), the clean coal and ash recovered by entrainment can be separated from the clean coal and ash recovered by attachment to bubbles.

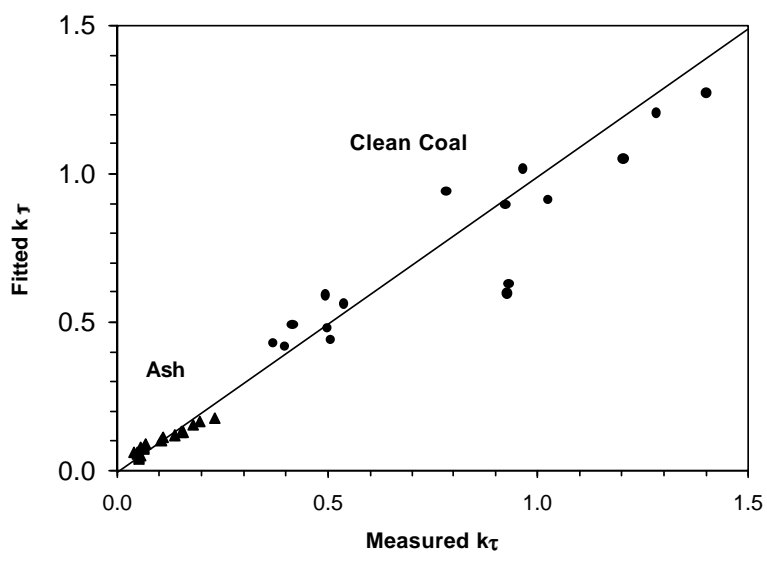

Figure 10. Multisize model fit compared with experimental values.

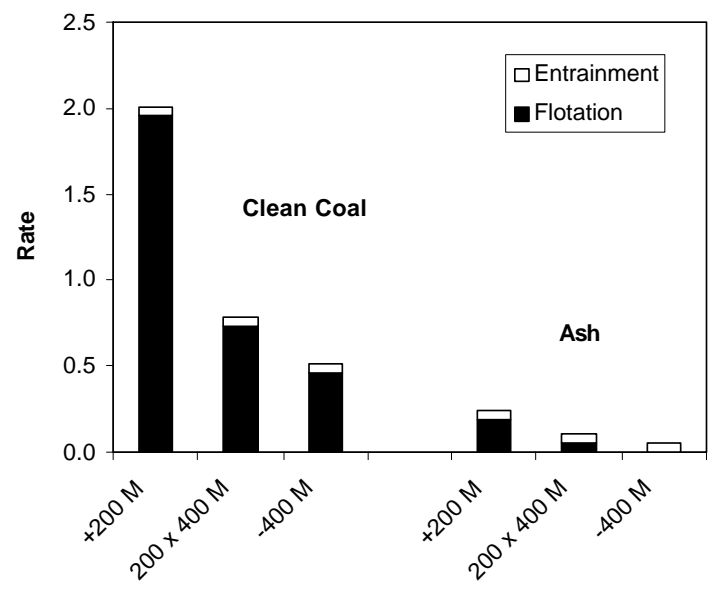

Figure 11. Entrainment and flotation rate contributions to total rate.

As shown, the detailed model is capable of predicting the experimental flotation rates quite adequately. Furthermore, the experimental data indicate that clean coal and ash recovery can be represented satisfactorily by considering bubble-particle attachment in combination with entrainment. As expected, the recovery of clean coal by entrainment is relatively insignificant in comparison to recovery by bubble-particle attachment; however, the entrainment recovery of ash is especially significant in the fine size range (-400 mesh). Based on the success of the detailed model, the next step was model simplification for use in on-line control.

Model Simplification: When adapting this detailed model for use in model-based control, the on-line model must be simple for quickness and robustness; yet it must not be so simple that it fails to approximate the first order behavior of the process. It is significant to note that the detailed model of Mika and Fuerstenau has been successfully reduced to a practical form and 
used on-line for the control of copper flotation (Zaragosa and Herbst, 1988). In the case of coal flotation, simplification of the detailed model requires the following steps:

1) Decide how simple the model must be in order to be practical.

2) Determine how many components and how many sizes must be included to achieve reasonable predictions.

3) Examine the general equations in light of known coal behavior to assess the relative importance of various terms.

4) Test the simplified model in the plant. Compare the full model response to the simplified model for extrapolation purposes.

Based on the data collected from the plant audit and the use of that data in estimating parameters for the detailed model, the following assumptions were developed to produce the simplified model:

1) Coal is a highly hydrophobic material so that the rates of attachment in both pulp and froth phases are much larger than detachment, i.e., $k_{i j}^{P A T} \gg k_{i j}^{P D T}$ and $k_{i j}^{F A T} \gg>k_{i j}^{F D T}$. This is not a good assumption for hydrophilic or weakly hydrophobic ash particles, and it introduces a certain amount of error into the predictive capabilities of the model since attachment and detachments rates are affected by the manipulated variables differently. However, since entrainment of ash particles is more significant than flotation of ash particles the error is not serious. Thus, particle detachment is not considered in the simplified model.

2) Drainage of water from froth to pulp is much less than entrained water from pulp to froth, i.e. $Q_{E} \gg Q_{R}$. Drainage is more important in flotation cells that have wash water added to the froth, such as flotation columns. Thus, drainage flows are ignored in this analysis. 
3) The small amount of middlings material present in this coal (see Figure 12 and Appendix B) means that the sample can be represented by two composition classes; a class containing $100 \%$ carbonaceous material to be referred to as "clean coal" and a class containing $100 \%$ mineral matter to be referred to as "ash".

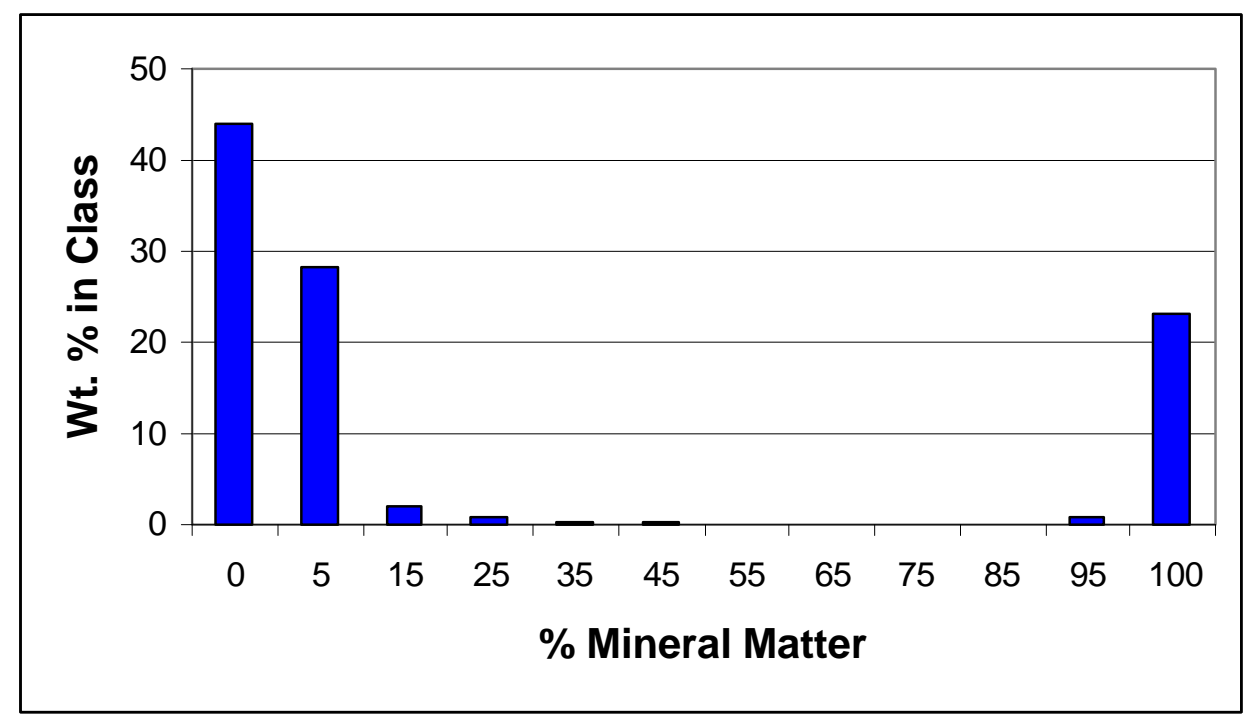

Figure 12. Particle composition distribution for the feed sample from factorial test 2 (note: Since compositional information was unavailable on -400 mesh material, the -400 mesh material was assumed to be fully liberated in constructing this plot.)

4) The feed size distribution to the flotation circuit is, to a reasonable approximation, constant for a given coal blend (see Appendix B); therefore, a size-averaged or size lumped-model should be acceptable in this case.

5) The solids in each cell are to a good approximation well mixed based on the results of the residence time distribution analysis (see Figure 6).

6) Attachment rate constants can be approximated as linear functions of the manipulated variables over the practical operating range of these variables.

Based on assumptions 1 - 5, the following model was obtained for each flotation cell $n$ where $n=1$ to 4 in this application: 
$\frac{d\left(V^{n} m_{C}^{n}\right)}{d t}=Q_{F}^{n-1} m_{C}^{n-1}-Q_{F}^{n} m_{C}^{n}-Q_{E}^{n} m_{C}^{n}-k_{C} V^{n} m_{C}^{n}$

$\frac{d\left(V^{n} m_{A}^{n}\right)}{d t}=Q_{F}^{n-1} m_{A}^{n-1}-Q_{F}^{n} m_{A}^{n}-Q_{E}^{n} m_{A}^{n}-k_{A} V^{n} m_{A}^{n}$

In this case $V^{n}$ is the pulp volume $\left(\mathrm{m}^{3}\right)$ in cell $n, m_{C}^{n}$ and $m_{A}^{n}$ are coal and ash concentrations $\left(\mathrm{kg} / \mathrm{m}^{3}\right), Q_{F}^{n}$ and $Q_{E}^{n}$ are volumetric flow of pulp feed and net entrainment rate of pulp $\left(\mathrm{m}^{3} / \mathrm{sec}\right)$, and $k_{C}$ and $k_{A}$ are the size lumped flotation attachment rate constants for coal and ash $\left(\sec ^{-1}\right)$, respectively.

Furthermore, based on assumption 6, the dependencies of $k_{A}$ and $k_{C}$ on manipulated variables (level $\ell$, collector $c$, and frother $f$ ) can be obtained from empirical relationships established from the plant audit data. These relationships have the form:

$k_{C} \tau=k_{C} \tau_{0}\left(1+\alpha_{C, \ell} \delta \ell+\alpha_{C, c} \delta c+\alpha_{C, f} \delta f\right)$

$k_{A} \tau=k_{A} \tau_{0}\left(1+\alpha_{A, \ell} \delta \ell+\alpha_{A, c} \delta c+\alpha_{A, f} \delta f\right)$

where $\mathrm{C}$ and $\mathrm{A}$ refer to the species (i.e., clean coal and ash), $k_{C} \tau_{0}$ and $k_{A} \tau_{0}$ represent baseline values of flotation rate, and $\alpha$ is a fitting constant. Thus, Equations 7-10 represent the simplified model used in this investigation for model-based control.

Simulator Development: The model described in Equations 7-10 was incorporated into a dynamic flotation bank simulator written in the $\mathrm{C}++$ language. The use of $\mathrm{C}++$ makes it possible to create object-oriented code which is more robust and amenable to future modification. In addition to the flotation bank object, a generic Kalman filter object was coded for use in on-line parameter estimation for the model. Finally, an optimization object was included to provide a mechanism for on-line optimization of the control strategy. 
Control Strategy Selection and Evaluation: The effectiveness of a given coal cleaning device is limited to a relatively narrow size range. This limitation forces modern coal processing plants to treat feed coals that have been sized into several different fractions, e.g., coarse (plus $10 \mathrm{~mm}$ ), intermediate $(10 \times 1 \mathrm{~mm})$, fine $(1 \times 0.15 \mathrm{~mm})$ and ultrafine (minus $0.15 \mathrm{~mm})$. The overall clean coal yield $(Y)$ and ash in the product $(A)$ for a plant consisting of $N$ total processes can be calculated from simple weighted averages given by:

$$
\begin{aligned}
& Y=\sum_{j=1}^{N} W_{j} y_{j} / \sum_{j=1}^{N} W_{j} \\
& A=\sum_{j=1}^{N} W_{j} y_{j} a_{j} / \sum_{j=1}^{N} W_{j} y_{j}
\end{aligned}
$$

in which $W_{j}$ is the weight percentage of feed coal reporting to circuit $j, y_{j}$ is the clean coal yield from the separator in circuit $j$, and $a_{j}$ is the coal quality produced by the separator in circuit $j$. Each size fraction may be cleaned to a different extent depending on the particular equipment settings selected by the plant operator. As a result, an infinite variety of yields and qualities can be obtained for the overall plant.

The goal of an effective plant operator is to select operating points for each process that will maximize the plant yield subject to a quality constraint imposed by the customer. Unfortunately, many plant operators choose to operate their plants so that each circuit produces the same clean coal quality. While this practice ensures that the quality constraint imposed by Equation 12 is not exceeded, this approach rarely maximizes the total yield of clean coal defined by Equation 11. In fact, the optimal operating conditions can be determined directly by combining Equations 11 and 12 and differentiating with respect to the individual circuit yields. 
The result of this calculation shows that plant yield (Y) can be maximized at an average clean coal ash (A) when all plant circuits are operated such that:

$$
A_{I}=\frac{\partial\left(y_{j} a_{j}\right)}{\partial y_{j}}=\text { Target }
$$

The incremental quality $\left(A_{I}\right)$ is simply the ash content of the last increment of coal recovered by a given process when the yield is changed by an infinitesimally small amount. Note that this principle is independent of the inherent washability characteristics of the coal (or coals) being processed and the relative proportions of material treated by each circuit.

A constant incremental ash can be achieved for circuits treating coarse and intermediate size particles by maintaining proper densities in the heavy medium separators. The same methodology cannot be used, however, for surface-based separation processes such as froth flotation. This is unfortunate since the largest discrepancy between "normal" and "optimized" incremental ash values often occurs in the froth flotation circuit.

In light of the above discussion, the most appropriate control objective, and the one preferred by Pittston representatives in this application, is to maintain a constant incremental ash in the froth flotation circuit. Because there is no direct sensing technology for incremental ash, this objective can only be accomplished using a model-based methodology. The model based strategy uses on-line models for minute-to-minute decision making. Furthermore, the models help the control system get the most out of limited instrumentation by determining in what state the process is at a given time and allowing the calculation of the manipulated variable trajectories which will move the process to a more desirable operating point state.

The model-based methodology for maintaining constant incremental ash can be described as follows. The incremental ash for a flotation circuit will depend on feed ash, the ratio of coal 
recovery rate to ash recovery rate (amenability), and the value of manipulated variables such as pulp level, collector and frother. All circuits are subject to random disturbances that cause $A_{I}$ to vary in the uncontrolled mode (see Figure 13).
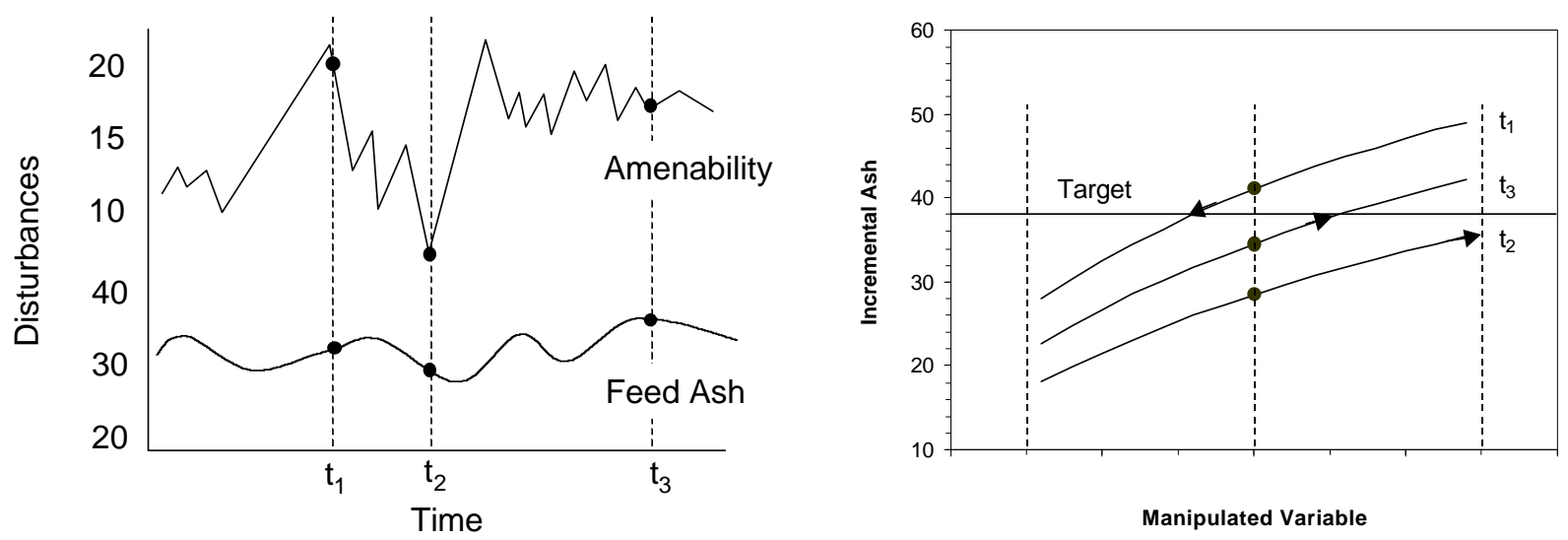

Figure 13. Conceptual design of incremental ash control system.

The objective of the control system is to adjust one or more manipulated variables to bring $A_{I}$ as close to the target value as possible for a given feed condition. In the case of Figure 13 at time $t_{1}$ the manipulated variable can be reduced until the target $A_{I}$ is reached since this particular feed coal has a high amenability for separation. At time $t_{2}$ the manipulated variable should be increased since the circuit is now processing a more difficult to treat coal; however, the maximum value of the manipulated variable may be reached before the incremental ash increases up to the target value. In this case, the optimum $A_{I}$ is given by the best that can be obtained by manipulating only one variable. Finally for the disturbance at time $t_{3}$, the manipulated variable can be increased from the uncontrolled value until the target value is achieved.

In the current study a model-based calculation is used to determine how much of a change in the manipulated variable is required to obtain the desired incremental ash. This involves solving the model equations and calculating the incremental ash from Equation 13 for a given combination of manipulated variables. This latter calculation requires knowledge of the 
system state (e.g. feed coal properties) at all times. This knowledge comes from a sequential estimator (in this case a Kalman Filter [Herbst et al., 1980]).

At the Moss \#3 plant there is an option to manipulate one or more of the variables: level, collector, and frother. Figure 14 shows that $A_{I}$ is quite sensitive to level changes, but less sensitive to collector and frother changes (note: All manipulated variables (MV) are plotted in normalized form; i.e., $\frac{M V-M V_{M e a n}}{M V_{M a x}-M V_{M i n}}$, so that they can be represented using a single x-axis.)

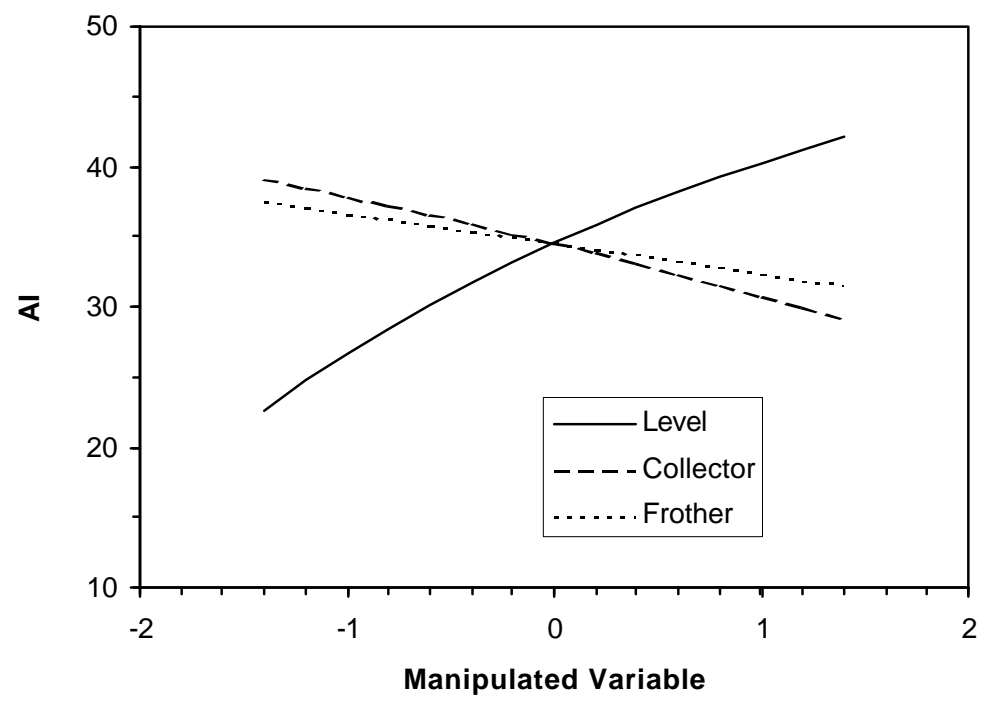

Figure 14. Sensitivity of incremental ash to changes in manipulated variables.

Thus, level was chosen as the single manipulated variable for control strategy development and testing.

Figures 15 and 16 show the simulated response of $A_{I}$ to changes in pulp level over the practical range 61 inches (from the bottom of the cell) to 67 inches. Note that for this coal the yield ranges from 67.5 to $73.5 \%$ while the ash in the clean coal ranges from 3 to $10 \%$ producing an incremental ash which ranges from $21 \%$ to $42 \%$. The incremental ash target for this plant is between 27 and $38 \%$ which falls comfortably into the range calculated. 


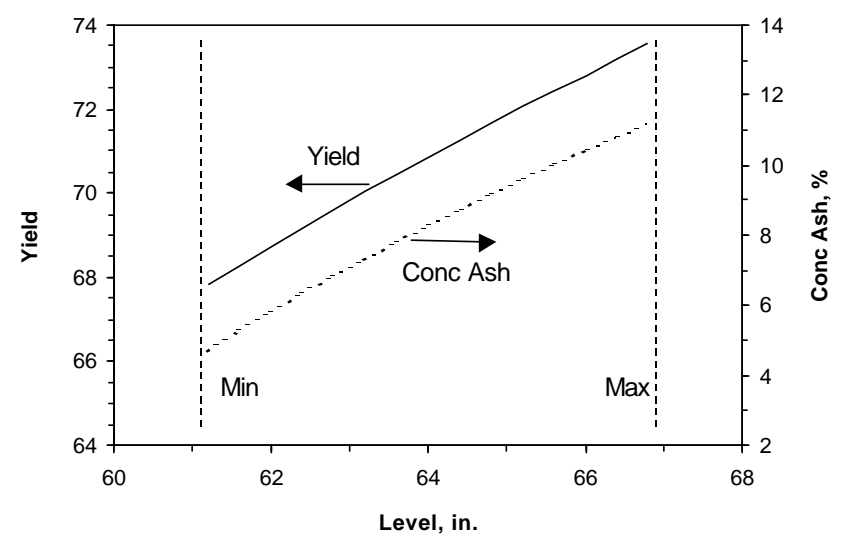

Figure 15. Yield and clean coal ash dependence on pulp level.

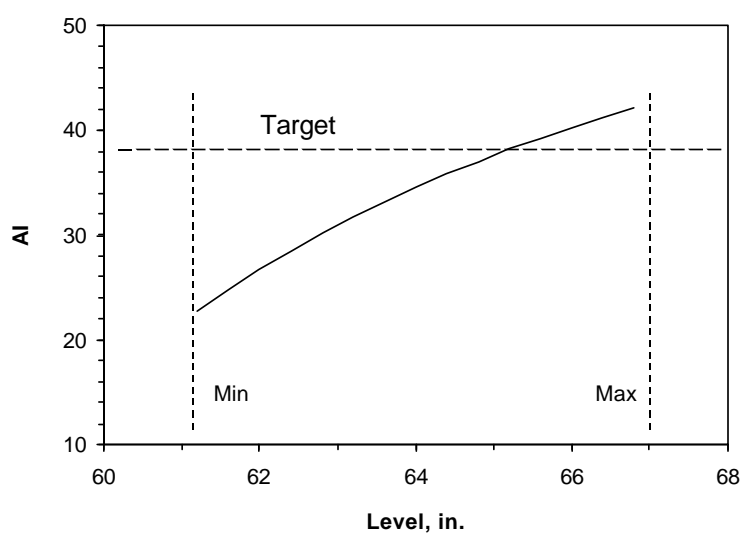

Figure 16. Incremental ash dependence on pulp level.

In order to characterize the kinetics of separation of various coals, $k_{A}, k_{C}, \tau$ and $Q_{E} / Q_{F}$

from Equations 9 and 10 were used in the form of amenability parameters. The parameters $k_{C} \tau$ $+Q_{E} / Q_{F}$ and $k_{A} \tau+Q_{E} / Q_{F}$, represent the overall recovery rates (flotation plus entrainment) for clean coal and ash, respectively. The ratio of these parameters represents the separation amenability.

As the amenability ratio for the coal changes, the ash content of the reject is expected to change significantly as shown in the simulations in Figure 17. Since an on-line measurement of reject ash is available from the video system, it should be possible to estimate the amenability ratio as it changes with coal type by using the model to compensate for other changes (such as pulp level) which may have occurred. In turn the amenability value can be used to determine the set point for pulp level which will allow the $\operatorname{target} A_{I}$ to be achieved.

Refer again to Figure 13, which showed possible scenarios concerning the dependence of $A_{I}$ on manipulated cell level. For a given amenability ratio, the level setpoint to achieve the $A_{I}$ target value (or the closest value) can be either searched for using a single variable (or multivariable) search algorithm or calculated using on-line model Equations 7-13. This is the approach used in the present investigation. 


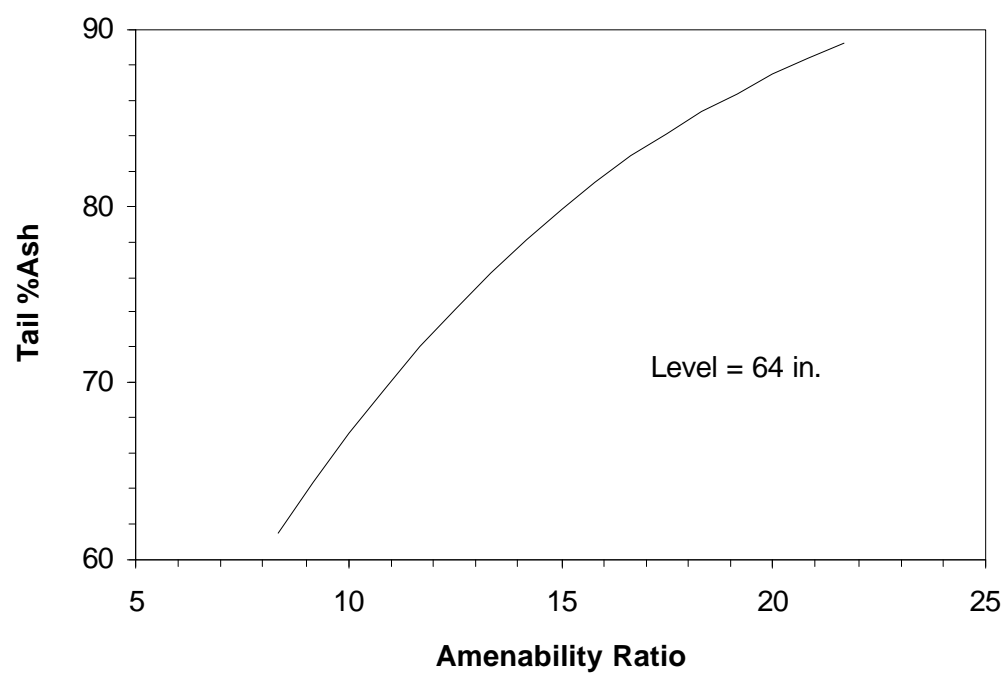

Figure 17. Influence of amenability ratio on tails ash.

Expert Supervisory System Development: Figure 18 shows the expert system logic. The Kalman filter and optimizer are calculation blocks in the expert system. The first rule block, Check Group I Emergency, are checks of measurements to determine if the flotation circuit is running and if so, is the ash analyzer functioning properly. To determine if the flotation circuit is running, the program tests digital signals from the plant controller that indicate whether or not the agitator in each cell is running. If at least three are running the flotation circuit is on. The plant feedrate must be greater than 500 tph (normally greater than 900 tph) for the strategy to continue with optimization. Collector and frother must also be within their normal range. The level and reject ash measurements also have to be within a normal range.

The second rule block, Check Group II Emergency, are checks of the Kalman filter estimates to determine if they are within their normal range. The most important of these is the amenability ratio. If it is too low or too high, numerical difficulties may be encountered in the optimizer so the optimizer is not run if the amenability ratio is not within normal range. The estimates of clean coal and ash concentrations in each of the four cells are also checked. 
Once it has been determined that the optimizer can calculate the optimum level, it does so and displays the result. If an operator gives permission, the expert systems then sends a new setpoint to the level controller.

Figure 18 is a simplification of the expert system because the Kalman filter processes the level measurement (a fast measurement) more frequently than the reject ash measurement (a slow measurement). A new reject ash measurement is available approximately every 3 minutes. Since the reject ash measurement is critical to the estimate of the amenability ratio and the optimum level setpoint is sensitive to the amenability ratio, the optimizer is run at the same frequency as the reject ash measurement. (Since the optimizer finds the optimum "steady state" level, attempting to optimize faster than 3 minutes would just yield values close to one another, until the next new reject ash measurement is available.)

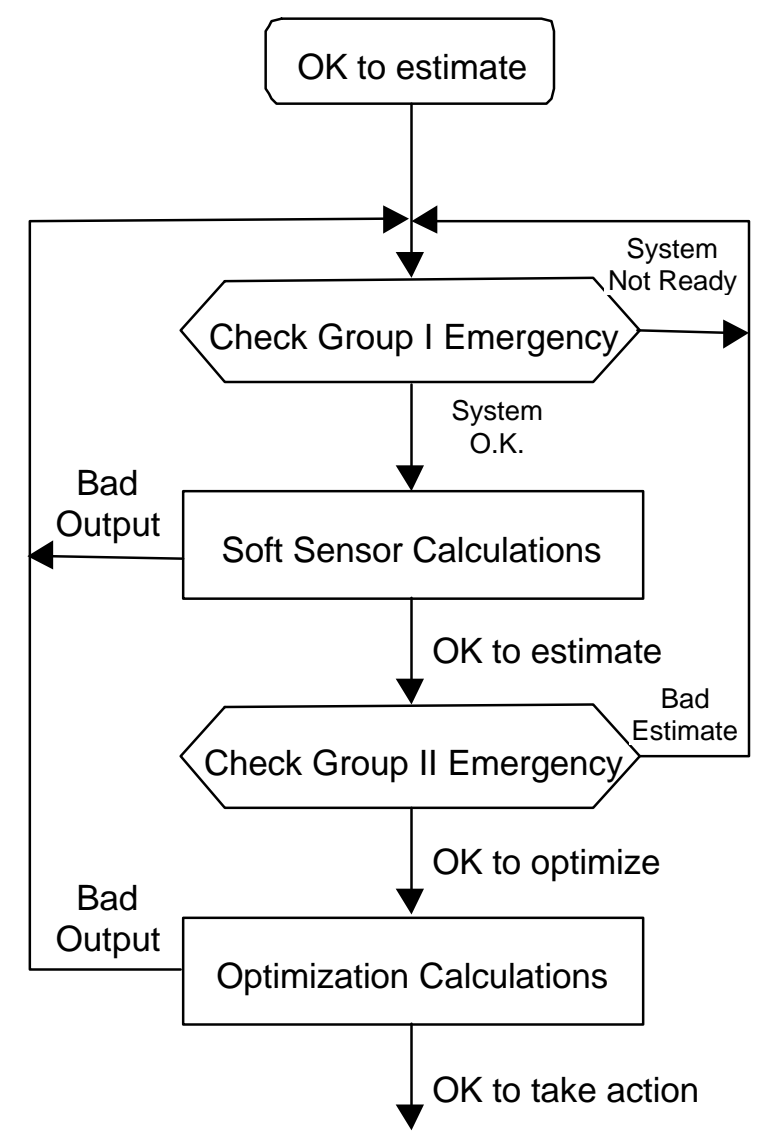

Figure 18. Expert system logic. 


\section{Sensor Testing}

Analyzer Description: A key variable to be measured for the coal flotation process is on-line ash. The primary analysis device being used in this investigation is a video-based ash analyzer developed at Virginia Tech under DOE grant DE-FG22-94PC94226 (Dunn et al., 1998).

The video-based analyzer consists of an image analysis system and a sample presentation system. The image analysis system is built around a personal computer operating in the Microsoft Windows environment. A frame-grabber is used to digitize images from a high speed, black-and-white television camera. All image processing operations are carried out using the BioScan OPTIMAS software. This package provides a C-type programming environment for the creation of specific image processing applications and graphical user interfaces. A separate video monitor serves as the primary image display device.

The sample presentation system, shown in Figure 19, consists of a PVC tube approximately $65 \mathrm{~cm}$ in length by $9 \mathrm{~cm}$ in diameter. The upper portion of the tube contains the camera, while the lower portion serves as the slurry presentation chamber. The upper and lower portions of the tube are bolted together with a Plexiglas disk and rubber gasket to ensure an airtight seal. The camera is held in place by a threaded PVC cap, with the camera lens placed against the Plexiglas disk. A small fan is used to prevent camera overheating. Sample illumination is provided by a ring light mounted around the camera lens. A Teflon diffusing ring is placed between the ring light and the Plexiglas disk to "soften" the light and eliminate "hot spots" on the image. Constant illumination of the slurry sample is maintained through the use of a reference mounted in the corner of the image frame. A feedback control loop is used to adjust the light source to maintain the gray level reading of the reference at a predetermined value. The 
sample presentation system was designed to be easily inserted into a sump or tank, with the level of the slurry inside the sample chamber manipulated by controlling the air pressure.

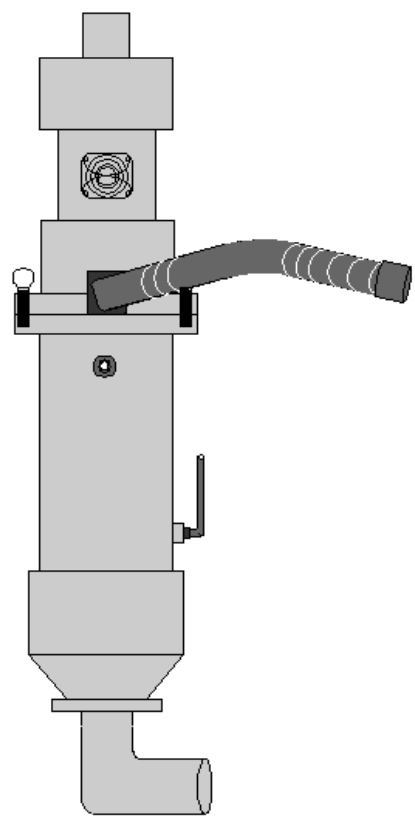

Front View

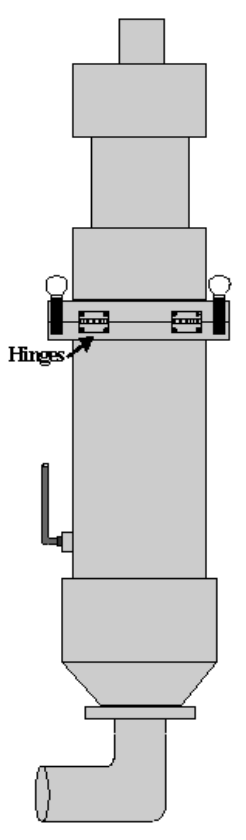

Back View

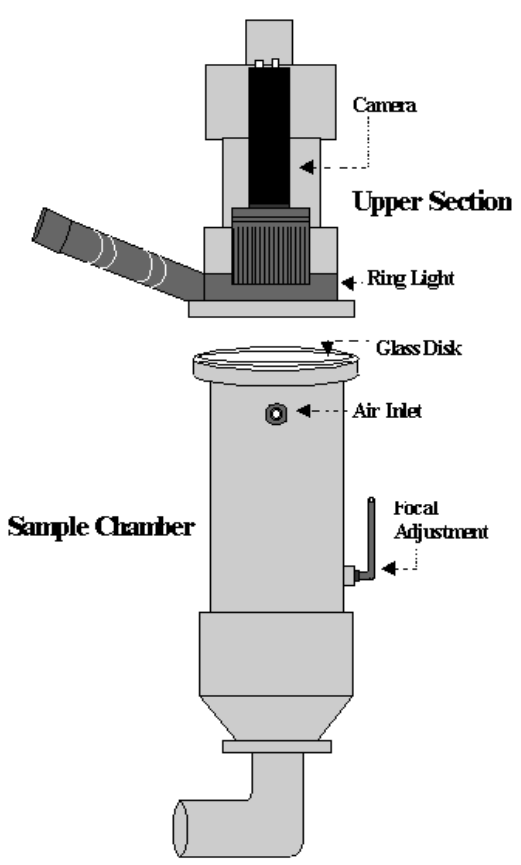

Figure 19. Schematic diagram of the video-based ash analyzer.

The final design of the video-based ash analyzer is shown schematically in Figure 20. The basic operating scenario can be described as follows. Slurry is fed to the sample sump from the flotation tailings stream. The solenoid air valve is actuated, permitting the acquisition of slurry into the sample presentation tube. The slurry rises to the focal plane of the camera, and an image of the slurry surface is captured. The computer digitizes the image and displays it on the television monitor. The software controlling the sensor takes average gray-level values obtained from multiple images and performs the necessary calculations to determine slurry ash content. The ash content is then displayed in an appropriate format. The entire operation requires approximately 15 seconds per image or 5 minutes for an analysis based on 20 images. 


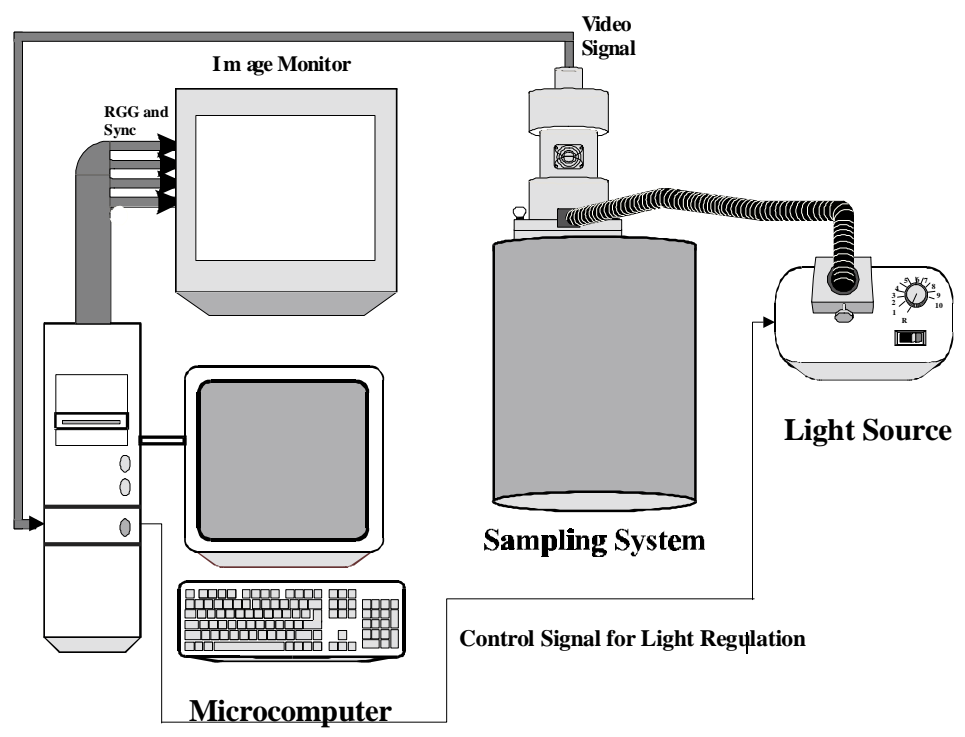

Figure 20. Overall schematic diagram of the video-based ash analyzer.

Analyzer Calibration: Initial testing of the video-based ash analyzer under grant DE-FG2294PC94226 was carried out at Pittston's Middle Fork preparation plant, a tailings pond reclaim operation that exhibits a highly variable feed. The device was installed to analyze the tailings from five flotation columns. The results obtained from this work indicate an accuracy of $73 \pm$ $4.0 \%$ ash based on a $90 \%$ prediction interval. The sensor was found to be best suited for analyzing flotation tailings ranging from $65-90 \%$ ash. Within this range, the device exhibited a relative error of $6.6 \%$. This level of accuracy appears to be comparable to many of the commercially available nuclear ash analyzers (Kawatra, 1993).

In the present project, similar results were obtained at the Moss No. 3 plant. Approximately 50 calibration points were obtained over a six-month period. The resulting calibration curve is shown in Figure 21. As shown, a linear trend exists between slurry ash content and mean gray level. Based on the scatter in the data, it appears that tailings ash content 
can be predicted within $\pm 2.5 \%$ ash. This is in-line with previous data collected during the development of the sensor (Dunn et al., 1998). Perhaps of more interest, however, is the fact that only two of data points collected during this period fell below $80 \%$ ash. This amounts to less than $5 \%$ of all the samples collected. It is a known fact that the installation of a control system and the constant monitoring of a process during this installation period often leads to increased attention to the process by plant personnel. It is possible that the remarkable performance of the Moss No. 3 flotation section during the six months sensor calibration period may be attributed to increased attention by plant personnel. The complete data set used in this analysis can be found in Appendix $C$.

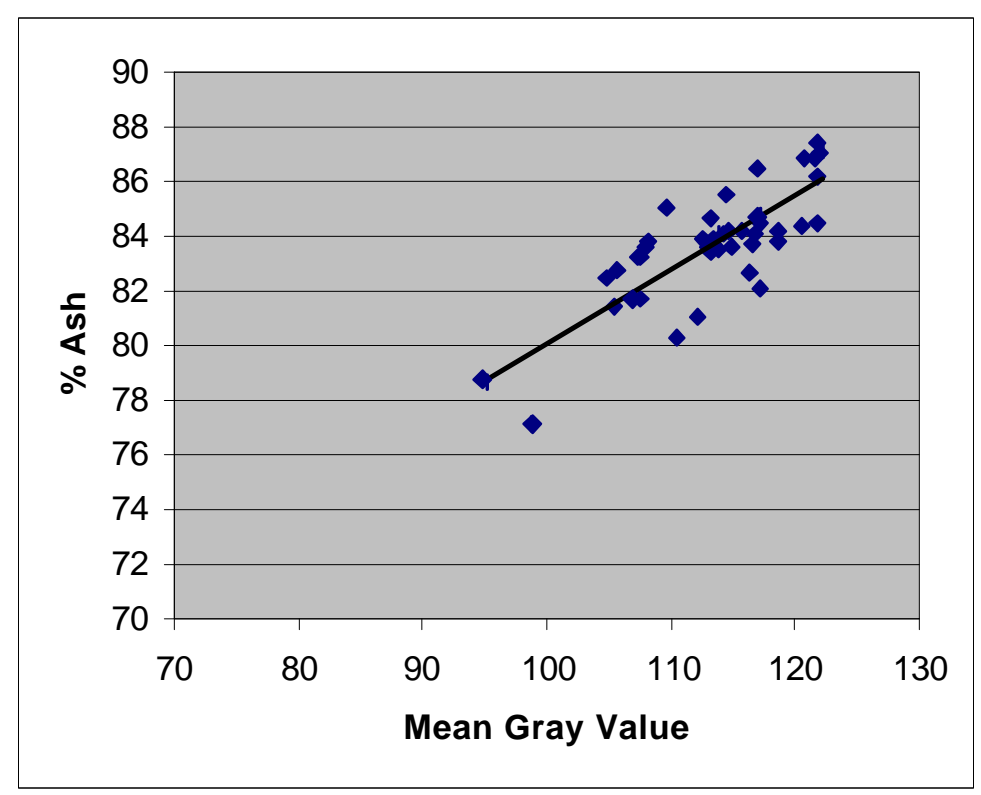

Figure 21. Calibration plot for the video-based ash analyzer showing data points obtained from April through September, 1998. 


\section{$\underline{\text { Operation and Testing }}$}

System Start-Up and Shakedown Testing: The implementation of the optimization strategy outlined previously was initiated by interfacing the supervisory computer (Dell Optiplex 350 $\mathrm{MHz}$ PC) to the plant Distributed Control System and field controllers. This interface is illustrated in Figure 22 and Table 2. As shown, the measurements in Table 2 are picked up by a Modicon 1384 controller. The Modbus Network allows these same measurements to be shared by the supervisory PC. Most control system functions take place in the Modicon except level control for the cell, which takes place in a Powell controller. The level setpoint is sent to the Powell controller on a 4-20 mA current loop connected to an analog I/O port in the Powell controller. The control program in the Powell controller was modified to accept the setpoint either from the supervisory PC or from the controller's front panel (as is normally done).

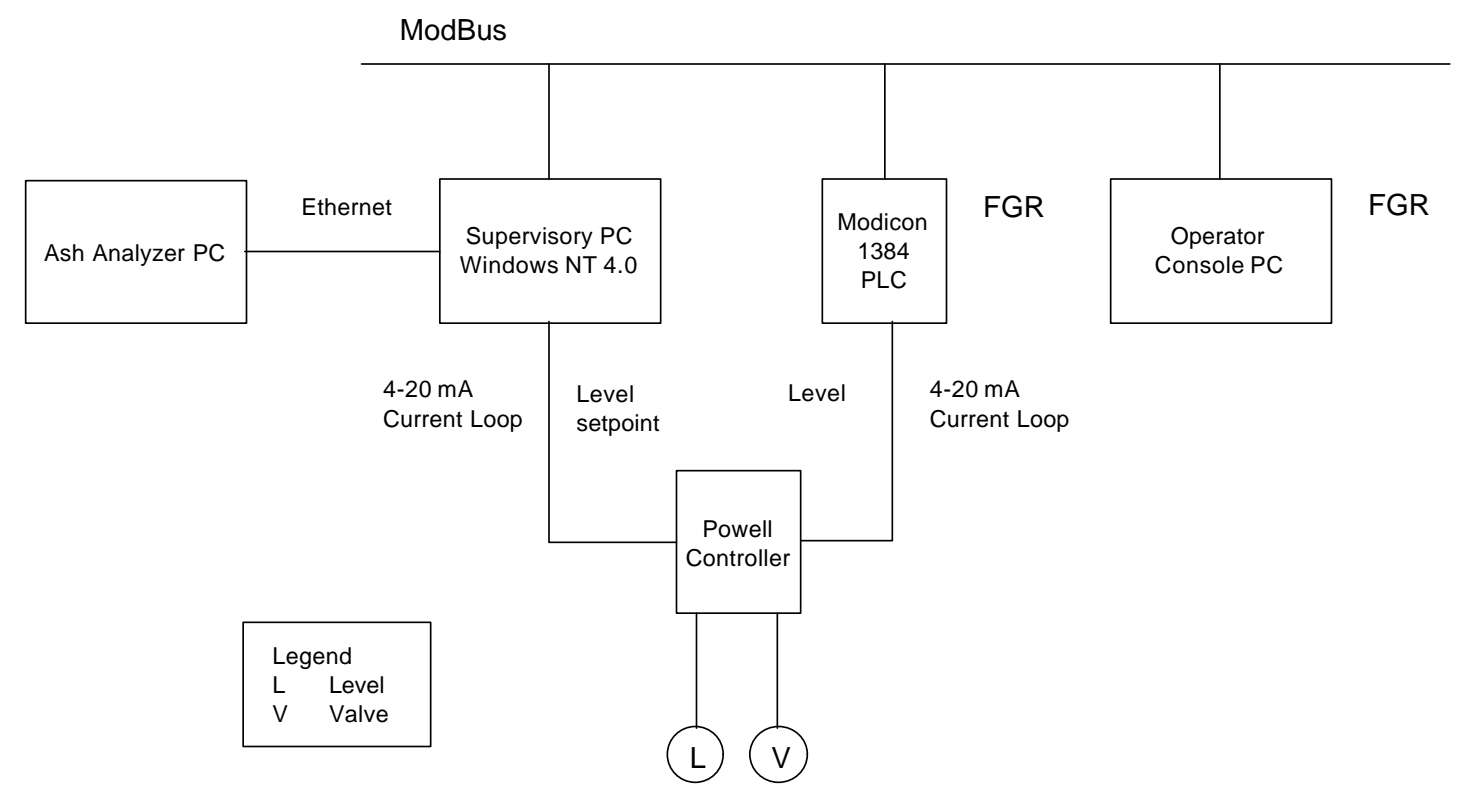

Figure 22. Interfacing the supervisory PC to the flotation circuit and control system. 
Table 2. Supervisory PC I/O to Flotation Circuit and Control System

\begin{tabular}{cc}
\hline Inputs & Outputs \\
\hline Fuel oil metering rate & Level setpoint \\
Reagent metering rate & \\
Agitator status for cells 1-4. & \\
Filter tub level (after the flotation circuit) & \\
Plant feedrate & \\
\hline
\end{tabular}

The control strategy was implemented in the supervisory PC with a model object, a sequential estimator object, and an optimization object embedded in a Visual Basic container. The main screen in shown in Figure 23. A description of the user interface "groups" in Figure 23 is given in Table 3.

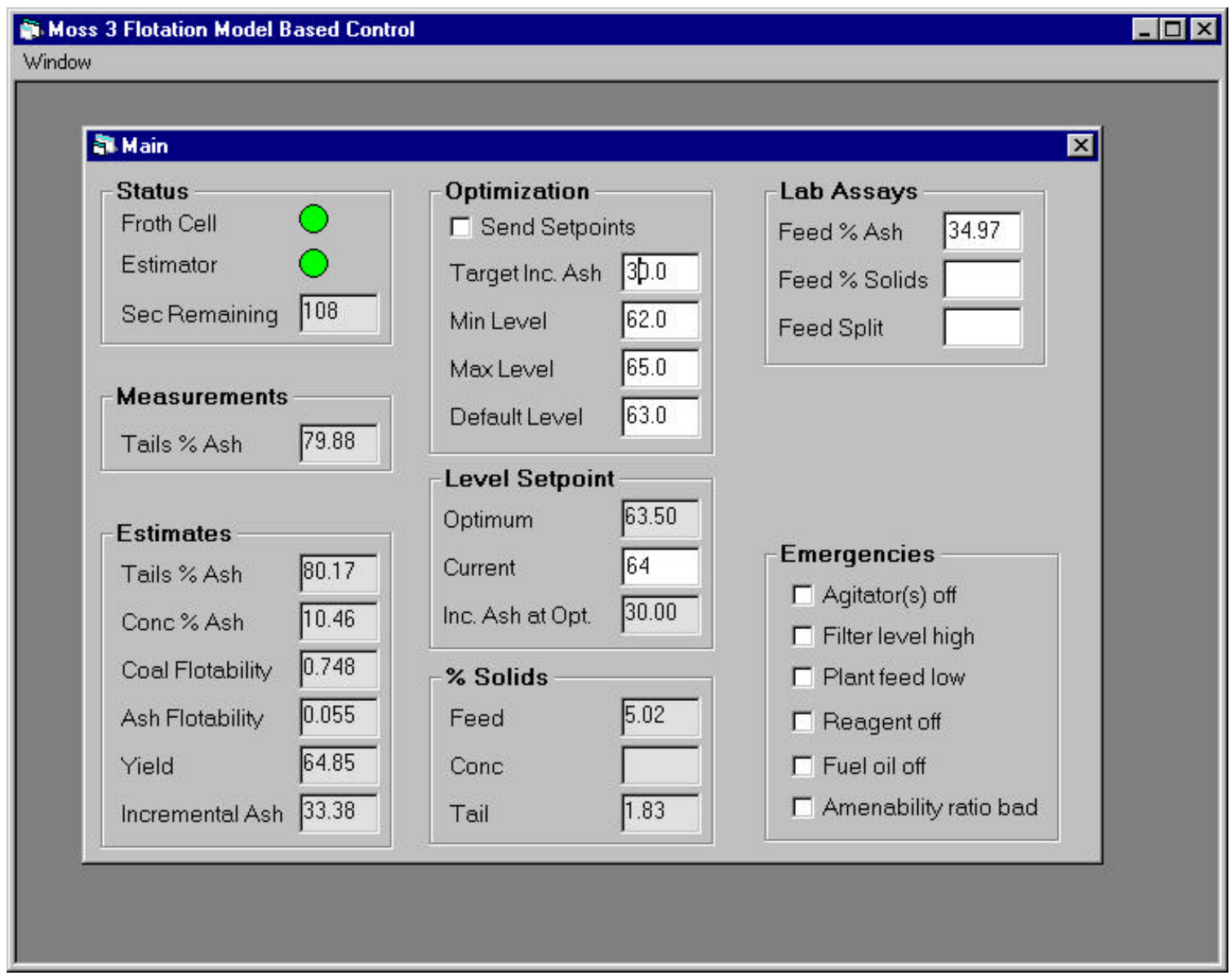

Figure 23. Main screen of the control program. 
Table 3. Summary of Expert System Operator Interface

\begin{tabular}{|c|c|}
\hline \multicolumn{2}{|l|}{ Status Group } \\
\hline Froth Cell & $\begin{array}{l}\text { Green if flotation circuit is running, red if it is } \\
\text { not }\end{array}$ \\
\hline Estimator & $\begin{array}{l}\text { Green if estimates appear to be valid, red if } \\
\text { they are not }\end{array}$ \\
\hline Sec Remaining & $\begin{array}{l}\text { Number of seconds until the next optimum } \\
\text { level setpoint } \mathrm{i}\end{array}$ \\
\hline \multicolumn{2}{|c|}{ Measurements Group } \\
\hline Tails \% Ash & Last measurement from the analyzer \\
\hline \multicolumn{2}{|l|}{ Estimates Group } \\
\hline Tails \% Ash & Current estimate from Kalman filter \\
\hline Conc \% ash & $\begin{array}{lllll}" & " & " & " & " \\
\end{array}$ \\
\hline Coal Flotability & " \\
\hline Ash Flotability & " $\quad$ " $\quad " \quad "$ \\
\hline Yield & " \\
\hline Incremental Ash & 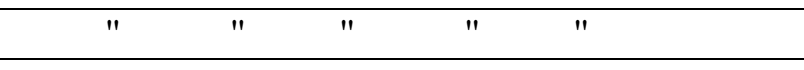 \\
\hline \multicolumn{2}{|c|}{ Optimization Group } \\
\hline Send setpoints & $\begin{array}{l}\text { If checked by operator the optimum level } \\
\text { setpoint is sent to the Powell controller }\end{array}$ \\
\hline Target Inc. Ash & $\begin{array}{l}\text { Optimizer finds the level setpoint that results in } \\
\text { this incremental ash }\end{array}$ \\
\hline Min. Level & Lowest setpoint that can be sent to controller \\
\hline Max Level & Highest setpoint that can be sent to controller \\
\hline Default Level & $\begin{array}{l}\text { If "Send setpoint" is checked but Kalman filter } \\
\text { or optimizer cannot run properly, the expert } \\
\text { system sends this "safe" setpoint to the } \\
\text { controller }\end{array}$ \\
\hline \multicolumn{2}{|c|}{ Level Setpoint Group } \\
\hline Optimum & The value found by optimizer \\
\hline Current & Measured value \\
\hline Inc. Ash at Opt. & $\begin{array}{l}\text { Will be the same as the target if the level } \\
\text { setpoint is within the min and max values. } \\
\text { Otherwise it is the incremental ash at the limit } \\
\text { level. }\end{array}$ \\
\hline \multicolumn{2}{|l|}{ \% Solids } \\
\hline Feed & Current value used in model \\
\hline Conc & Current estimate from Kalman filter \\
\hline Tails & Current estimate from Kalman filter \\
\hline
\end{tabular}


Table 3. (Continued)

\begin{tabular}{|c|l|}
\hline Lab Assays Group & \\
\hline Feed \% Ash & $\begin{array}{l}\text { Input by operator when a new value is } \\
\text { available (usually calculated by plant } \\
\text { superintendent from the blend of coals fed to } \\
\text { the plant }\end{array}$ \\
\hline Feed \% Solids & $\begin{array}{l}\text { Input by operator when a new value is } \\
\text { available (usually doesn't change) }\end{array}$ \\
\hline Feed Split & $\begin{array}{l}\text { Not used but reserved for possible future use if } \\
\text { the tonnage feeding the flotation circuit could } \\
\text { be calculated from the properties of the blend } \\
\text { of coals feeding the plant }\end{array}$ \\
\hline Emergencies Group & $\begin{array}{l}\text { Set by expert system if more than 1 agitator is } \\
\text { off }\end{array}$ \\
\hline Agitator(s) off & $\begin{array}{l}\text { Set by expert system if tub level of disk filter } \\
\text { for the conc is overflowing }\end{array}$ \\
\hline Filter level high & $\begin{array}{l}\text { Set by expert system if plant feedrate is less } \\
\text { than 500 tph }\end{array}$ \\
\hline Plant feed low & $\begin{array}{l}\text { Set by expert system if reagent feeder is low } \\
\text { (off) }\end{array}$ \\
\hline Reagent off & Set by expert system if fuel oil feed is low (off) \\
\hline Fuel oil off & $\begin{array}{l}\text { Set by expert system if ratio is less than 1 or } \\
\text { greater than 100. }\end{array}$ \\
\hline Amenability ratio bad & \\
\hline
\end{tabular}

A preliminary test of the strategy was carried out in September 1998. Results of this test are depicted in Figure 24. Here a series of pulp level setpoint changes were made (63 in., 64 in., 65 in., and 66 in.) over a 90 minute period with collector and frother constant. The impact on incremental ash, yield, and concentrate ash were calculated from the on-line model and estimator. Confirmation that the predicted changes in concentrate quality occur is obtained by noting that concentrate ash and incremental ash measurements made on grab samples at various points during the test period are reasonably close to the model predictions. The concentrate ash is determined in the usual manner while incremental ash is estimated by floating circuit tails for a brief time in a batch cell and measuring the ash content of the incremental batch product. It is significant to note that the range of $A_{I}$ values obtained from pulp level changes during this initial 
test period include what was expected to be the overall plant target value of $38 \%$. It is also significant to note that incremental ash is quite sensitive to manipulated variable changes.
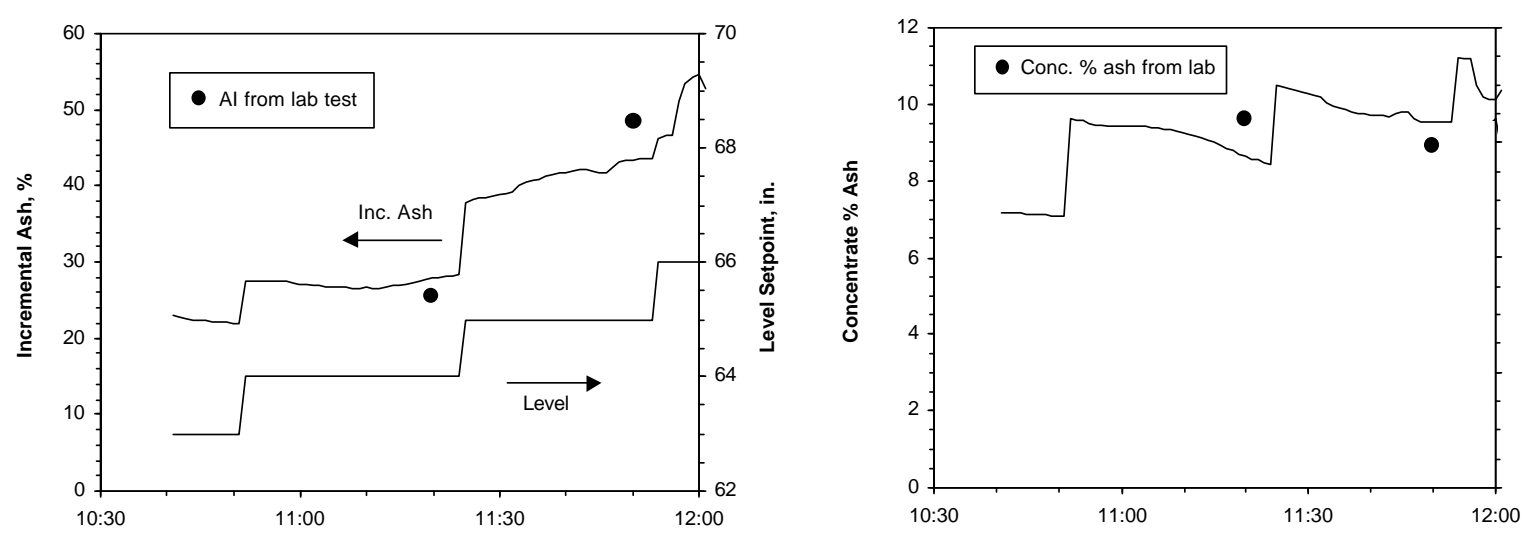

Figure 24. Plant test of controllability of incremental ash at Moss \#3.

Data Collection and Control Strategy Evaluation: Following the preliminary evaluation, a statistically designed on-off testing campaign was implemented during the period from November 16 to December 19, 1998 to test the following hypotheses:

1) The model based strategy is capable of maintaining incremental ash at a specified target.

2) The variance of the model based control of incremental ash is significantly smaller than current operator control.

As a first step, two hardsensors (the video-based ash analyzer and the level sensor) and a softsensor (the model for predicting flotability and incremental ash) were used to monitor the process without the model-based strategy being implemented. An example of such monitoring is shown in Figure 25. Note here that the uncontrolled $A_{I}$ varies from 25 to 45 as the operator manipulates the level setpoint. 

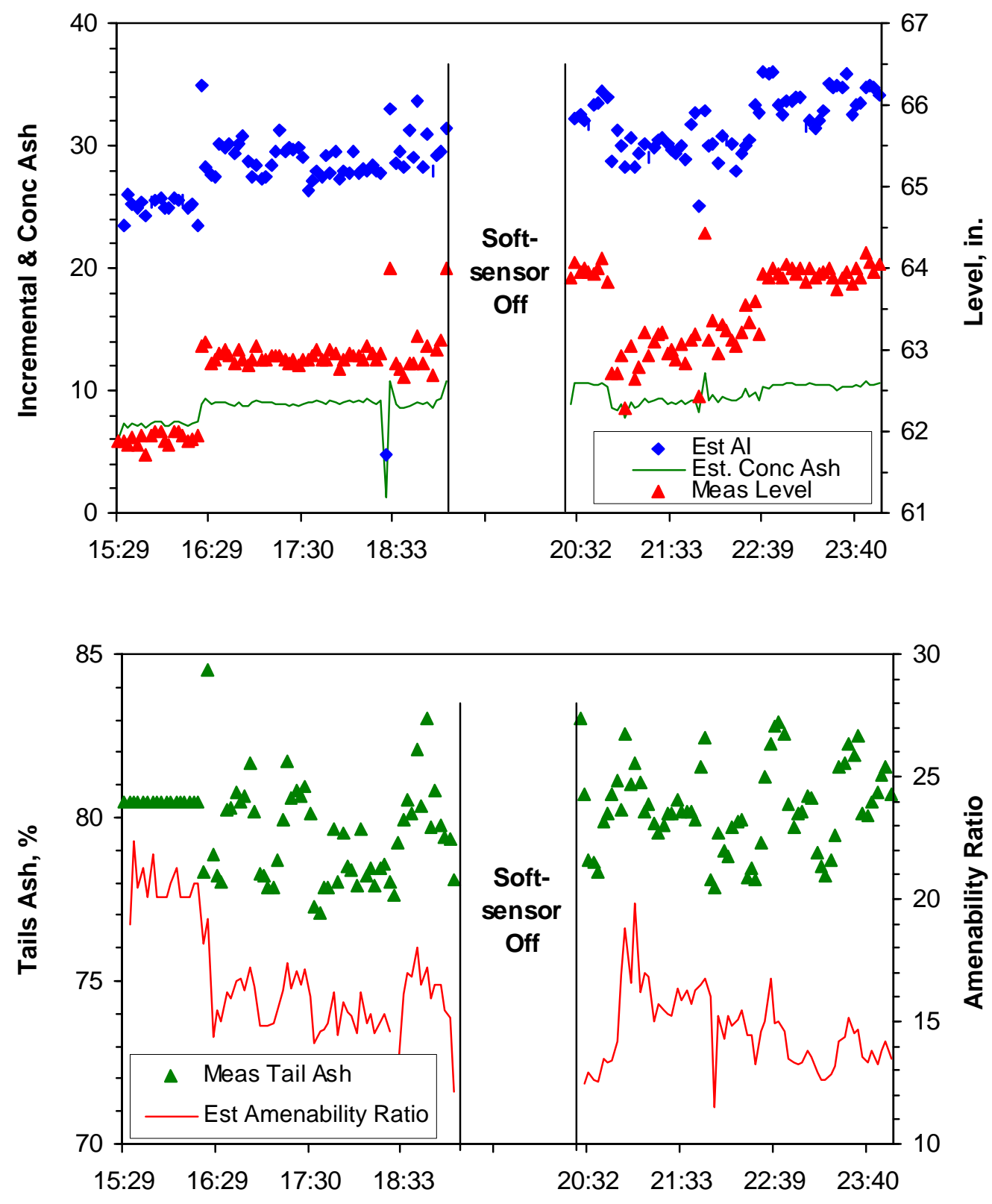

Figure 25. Standard plant operation baseline.

At the outset of the model based control evaluation we were informed that due to the potential for overloading the concentrate disk filter, the flotation cell levels had to be maintained below 63 in. This translated to $A_{I}$ target values of less than 30 . When actual on-off testing began the $A_{I}$ target was set to 27 . In Figure 26 we can see that the control system hits the target very quickly after the system is turned on and departs from the target when model based control 
is turned off. It is interesting to note that the ash analyzer appears to track the general trend in the reject ash as shown by the comparison with the composite shift ash values reported by Pittston.
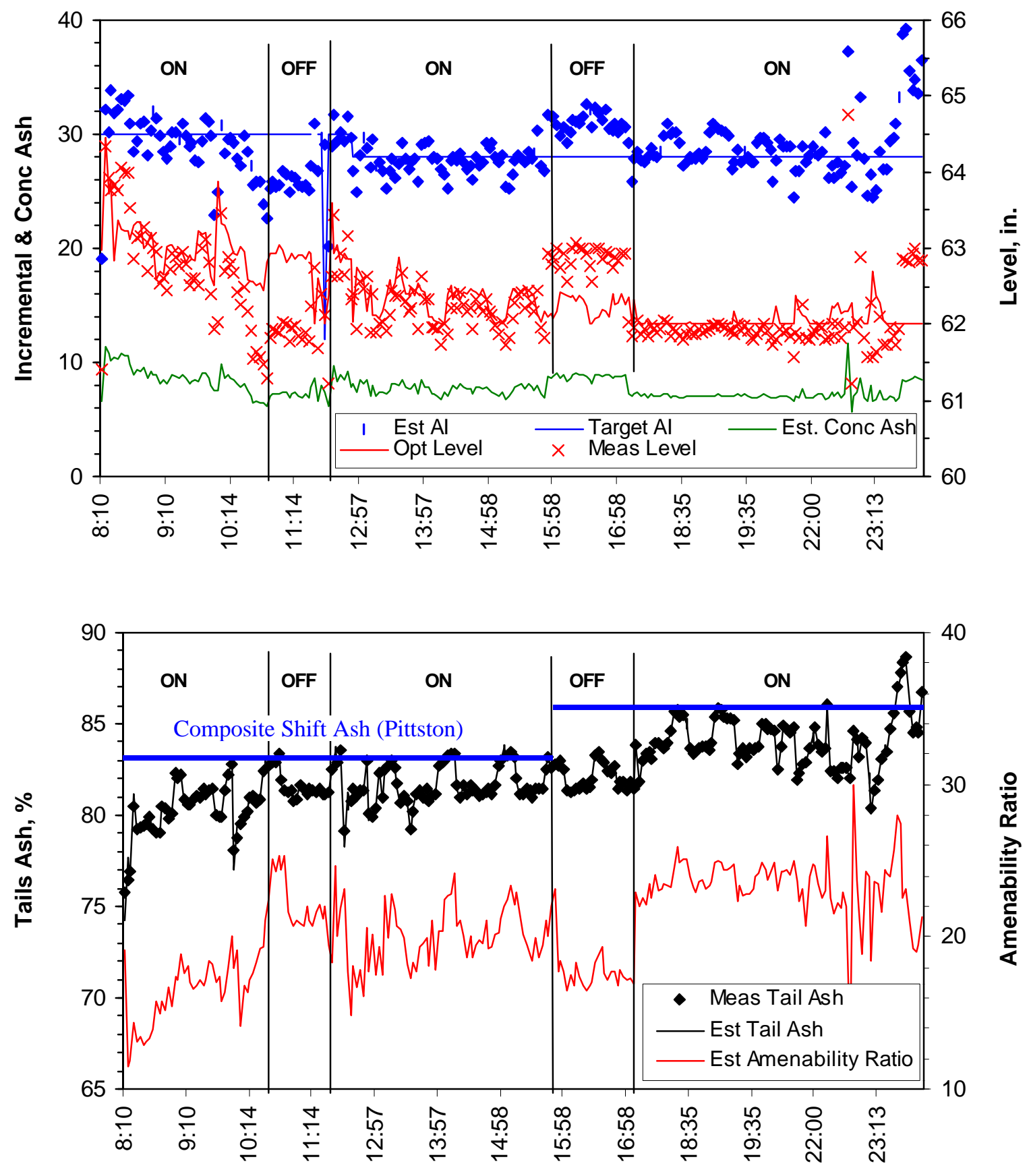

Figure 26. Short term on-off testing of control system performance. 
The complete on-off testing program was carried out between November 16 and November 18,1998 . During this period data was logged every three minutes in a text file that could be read later with Microsoft Excel for analysis. The historical data included the model state estimates, estimated variables such as amenability ratio, concentrate ash, status of emergency rules (in alarm or not) and the optimum level calculated by the optimizer.

The on-off testing regiment was set up with variable time intervals; however, approximately the same time was spent with control on and control off. The control target $\left(A_{I}=27.3\right)$ and the operating target $\left(A_{I}=29.5\right)$ were considered virtually identical for comparison purposes. Comparisons between control on and control off were made using a sum-of-squarederror on incremental ash defined as:

$$
S S_{A I}=\sum_{i=1}^{N} \frac{\left(A I_{\text {OBS }, i}-A I_{\text {Target }, i}\right)^{2}}{N}
$$

The values calculated for each day are given in Table 4.

Table 4. Analysis of Incremental Ash Data During On-Off Testing

\begin{tabular}{ccccc}
\hline Date & $\begin{array}{c}\text { Target } \\
\text { AI }\end{array}$ & $\begin{array}{c}\text { Mean } \\
\text { AI }\end{array}$ & $S S_{A I}$ & $\sqrt{S S_{A I}}$ \\
\hline Control On & & & & \\
$11 / 16$ & 27 & 26.8 & 2.08 & 1.44 \\
$11 / 17$ & 27 & 26.8 & 2.36 & 1.54 \\
$11 / 18$ & 28 & 28.5 & 2.70 & 1.64 \\
Control Off & & & & \\
$11 / 17$ & 29.5 & 29.8 & 13.30 & 3.65 \\
$11 / 18$ & 29.5 & 29.2 & 32.7 & 5.72 \\
\hline
\end{tabular}

The long term effectiveness of the model-based control system is shown in Figure 27 for a 7-hour test conducted in February, 1999. The flotation circuit was under model-based control throughout the test, and the system was operated by Pittston personnel. The standard deviation from the $\mathrm{A}_{\mathrm{I}}$ target of 27 is 1.42 , which is approximately 2.5 times smaller than that achieved under standard plant operation (the variance is 6 times smaller). The bottom line is that relative error with model based control was found to be about $5 \%$. 

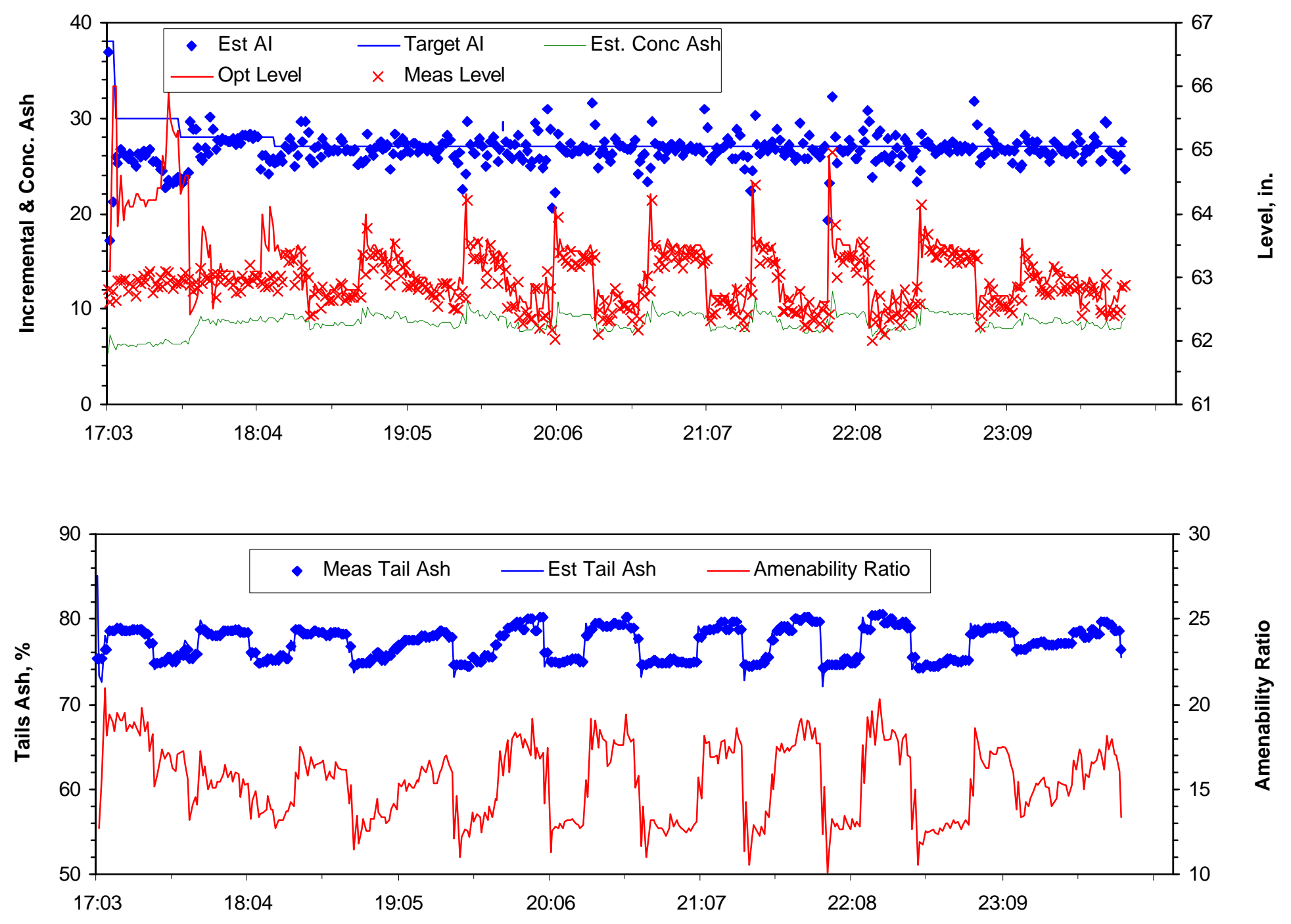

Figure 27. Long term control strategy performance at Pittston's Moss \#3. 


\section{System Evaluation}

From a technical perspective, the benefits of the model-based control scheme are very apparent. The standard deviation of the incremental ash was reduced by a factor of 2.5 over standard plant control, and the variance was reduced by a factor of 6 . In other words, the control system was able to maintain a much more stable operation. In addition, the model-based approach used here was able to provide information that would be impossible to obtain under normal circumstances. This information being on-line estimates of incremental ash and floatability. Furthermore, the video-based ash analyzer provided a reliable on-line measurement of tailings ash, and was found to track the general trend in tailings ash observed from composite shift measurements quite well.

From an economic perspective, the benefits of the model-based control system are more difficult to discern. This is primarily due to the fact that this particular application was limited by the capacity of the clean coal filter. Thus, the system could not operate at a true optimal incremental ash value. For instance, if the data shown in Figure 26 are used to calculate clean coal yield during the periods when the control system was on and when it was off, the average yield under model-based control was approximately $70.2 \%$, while the average yield under normal plant operation was approximately $70.6 \%$. These values are virtually identical for all practical purposes. At the same time, the average clean coal ash under model-based control was approximately $7.9 \%$, while the average clean coal ash under normal plant operation was approximately $8.4 \%$ ash. Once again, it is difficult to assign any significance to this difference. However, assuming the Pittston operation had not been limited by the clean coal filter and the control system had generated a very conservative increase in clean coal yield of $1 \%$ at a price of $\$ 25 /$ ton, this would have added approximately $\$ 125,000$ per year to the bottom line. At an 
installed cost of $\$ 45,000$ for the control system (as quoted by J.A. Herbst and Associates) and $\$ 15,000$ for the sensor, even such a small increase in yield would have resulted in a payback period of less than $1 / 2$ year.

It is clear from the data presented that the Moss No. 3 plant is a very well operated plant. Thus, producing a slight technical improvement at this operation is quite significant. Perhaps from the perspective of future commercial activity, it is important to note that Pittston is interested in applying this control system at another plant that has much more significant flotation control problems. The flotation circuit at this prospective test site came on-line during the course of this project. Had it been available when the project began, it would have most likely been Pittston's preference to conduct this study at that site. As it stands, Pittston has indicated an interest in installing a video ash analyzer at this new site as a first step toward process control. In addition, it is likely that J.A. Herbst and Associates will use the knowledge gained from this project to pursue further commercial activity in the Eastern U.S. coal industry. 


\section{CONCLUSIONS}

The purpose of this project was to implement an advanced control system for fine coal flotation and to demonstrate this system at an existing coal preparation plant. As a result of data collected during a plant sampling campaign, and subsequent discussions with plant engineers, a model-based control scheme was developed for optimizing flotation circuit performance by maintaining constant incremental ash. Two major features of this control systems are the use of a video-based ash analyzer for monitoring reject ash, and the use of a soft sensor for predicting incremental ash and floatability. Based on the data collected here, the following conclusions can be drawn:

1. The video-based ash analyzer is a technically feasible and economic alternative for on-line analysis of tailings slurries containing in excess of $65 \%$ ash. Its accuracy is comparable to that of nuclear-based analyzers, and it is nearly an order of magnitude less expensive. The long-term performance of the analyzer was shown to track the plant shift assays quite well.

2. A model-based estimator (i.e., soft sensor) can be used to effectively calculate the ash content of the last increment of coal recovered from a flotation bank (i.e., incremental ash). The manipulation of pulp level in its standard operating range allows a target value of incremental ash to be obtained.

3. The model-based control strategy employed here is capable of moving the plant to a given (feasible) target and keeping it there.

4. On-off testing of the model-based control strategy at Moss \#3 showed that this control strategy reduces the variance from a target incremental ash by about a factor of six. Longer

term testing of the strategy showed a relative error $\left(100 \sqrt{S S_{A I}} / A_{I, \text { Target }}\right)$ of about $5 \%$. 
5. During the course of this study it became apparent that in order for a model-based strategy like the one developed here to drive flotation to its best operating point day in and day out, other constraints such as the disk filter capacity at Moss \#3 must be eliminated or the constraint must be fully integrated into the strategy. 


\section{REFERENCES}

1. Bascur, O.A. and Herbst, J.A., 1982, "Dynamic Modeling of a Flotation Cell with a View Toward Automatic Control", Preprints XIV IMPC, Session III, Toronto, Oct. 17-23, CIM, p. III-11.1.

2. Dunn, P.L., Cruz, E.B., Luttrell, G.H. and Adel, G.T., 1998, "Development of a Video-Based Coal Slurry Ash Analyzer," Minerals and Metallurgical Processing, Vol. 15, No. 2, pp. 1-10.

3. Kawatra, S.K., 1993, "The Theory and Development of a Michigan Tech/Outokumpu Slurry Ash Analyzer," Emerging Computer Techniques For The Mineral Industry, B.J. Scheiner, D.A. Stanley, and C.L. Karr, eds., SME, Littleton, Colorado, pp. 259-270.

4. Mika, T.S. and Fuerstenau, D.W., 1969, "A Microscopic Model of the Flotation Process", V.2 IMPC Leningrad, Mekanobr, USSR, p. 246-269.

5. Herbst, J.A., Rajamani, K. and Pate, W.T., 1980, "Identification of Ore Hardness Disturbances in a Grinding Circuit Using a Kalman Filter," 3rd IFAC Symposium on Automation in Mining, Mineral, and Metal Processing, Montreal, Aug. 18-20, J. O’Shea and M. Polis, eds., Pergamon, New York, p. 333.

6. Zaragosa, R. and Herbst, J.A., 1988, "A Model-Based Feed Forward Control Scheme for Flotation Plants", Minerals and Metallurgical Processing, Vol. 5, p. 177-186. 


\section{NOMENCLATURE}

$a_{j} \quad$ - coal quality produced by the separator in circuit $j$.

A - overall plant ash content in clean coal product.

$A_{C} \quad$ - ash content of the concentrate (Appendix A).

$A_{F} \quad$ - ash content of the feed (Appendix A).

$A_{I} \quad$ - ash content of the last increment of coal recovered by a given process when yield is changed by an infinitesimally small amount (i.e., incremental ash).

$A_{l, O b s}$ - observed incremental ash from the flotation circuit.

$A_{l, \text { Target }}$ - incremental ash set-point.

$A_{T} \quad$ - ash content of the tailings (Appendix A).

$A_{C, l}^{d}$ - ash content of size class $l$ material in the concentrate stream (Appendix A).

$A_{F, l}^{d} \quad$ - ash content of size class $l$ material in the feed stream (Appendix A).

$A_{T, l}^{d} \quad$ - ash content of size class $l$ material in the tailings stream (Appendix A).

c - collector addition rate.

$\mathrm{C}(\mathrm{t})$ - concentration of tracer in the exit stream of a vessel (mass/volume).

$\mathrm{C}(0)$ - concentration of tracer in a vessel at time $=0$ (mass/volume).

$\delta c \quad$ - incremental change in collector addition rate.

$\delta f \quad$ - incremental change in frother addition rate.

$\delta \ell \quad-\quad$ incremental change in pulp level.

$f \quad$ - frother addition rate.

$f_{C, l} \quad$ - mass fraction of size $l$ in the concentrate (Appendix A).

$f_{F, l} \quad$ - mass fraction of size $l$ in the feed (Appendix A).

$f_{T, l} \quad$ - mass fraction of size $l$ in the tailings (Appendix A). 
$f_{C, k}^{d} \quad$ - particle composition class $k$ of size class $l$ material in the concentrate stream (Appendix A).

$f_{F, k}^{d} \quad$ - particle composition class $k$ of size class $l$ material in the feed stream (Appendix A).

$f_{T, k}^{d} \quad$ - particle composition class $k$ of size class $l$ material in the tailings stream (Appendix A).

i $\quad$ - size class.

j - composition class.

$k \quad-$ rate constant $\left(\right.$ time $\left.^{-1}\right)$.

$k_{A} \quad$ - size lumped flotation rate constant for ash $\left(\mathrm{s}^{-1}\right)$.

$k_{C} \quad$ - size lumped flotation rate constant for coal $\left(\mathrm{s}^{-1}\right)$.

$k_{i j}^{F A T}$ - particle attachment rate constant in the froth $\left(\right.$ time $\left.^{-1}\right)$.

$k_{i j}^{F D T}$ - particle detachment rate constant in the froth $\left(\right.$ time $\left.^{-1}\right)$.

$k_{i j}^{P A T}$ - particle attachment rate constant in the pulp $\left(\mathrm{time}^{-1}\right)$.

$k_{i j}^{P D T} \quad$ - particle detachment rate constant in the pulp $\left(\operatorname{time}^{-1}\right)$.

$k_{i j}^{R} \quad$ - dimensionless classification constant representing the segregation of particles occurring in the draining liquid of the froth.

$\ell \quad$ - pulp level in the cell.

$m_{a} \quad$ - concentration of ash in flotation cell $n\left(\mathrm{~kg} / \mathrm{m}^{3}\right)$

$m_{c} \quad$ - concentration of coal in flotation cell $n\left(\mathrm{~kg} / \mathrm{m}^{3}\right)$.

$M_{C} \quad$ - mass flow rate of pulp in the concentrate stream (Appendix A).

$M_{F} \quad$ - mass flow rate of pulp in the feed stream (Appendix A).

$M_{T} \quad$ - mass flow rate of pulp in the tailings stream (Appendix A).

$M V \quad$ - manipulated variable (e.g., pulp level, frother addition rate, collector addition rate). 
$M V_{M a x}$ - maximum value of the manipulated variable.

$M V_{\text {Min }}$ - minimum value of the manipulated variable.

$M V_{\text {Mean }}{ }^{-}$mean value of the manipulated variable.

$n \quad$ - individual flotation cell.

$\mathrm{N} \quad$ - number of perfect mixers in series.

$p_{C} \quad$ - percent solids in the concentrate stream (Appendix A).

$p_{F} \quad$ - percent solids in the feed stream (Appendix A).

$p_{T} \quad-$ percent solids in the tailings stream (Appendix A).

$Q_{A} \quad$ - volumetric flow rate of air into the flotation bank (volume/time).

$Q_{A C} \quad$ - volumetric flow rate of air leaving the top of the froth (volume/time).

$Q_{A T} \quad$ - volumetric flow rate of air leaving with the tailings stream (volume/time).

$Q_{C} \quad$ - volumetric flow rate of liquid leaving with the concentrate (volume/time).

$Q_{E} \quad$ - volumetric flow rate of water transported to the froth due to entrainment in the bubble film and wake (volume/time).

$Q_{F} \quad$ - volumetric flow rate of liquid in the feed stream (volume/time).

$Q_{\text {Feed }}$ - volumetric flow rate of liquid in the feed stream (volume/time).

$Q_{R} \quad$ - volumetric flow rate of water draining from the froth (volume/time).

$Q_{T} \quad$ - volumetric flow rate of liquid in the tailings stream (volume/time).

$S S_{A I} \quad$ - sum-of-squared error between target and observed incremental ash.

t $\quad$ - time.

$V \quad$ - pulp volume in cell $\left(\mathrm{m}^{3}\right)$

$V_{B F} \quad$ - volume of air in the froth. 


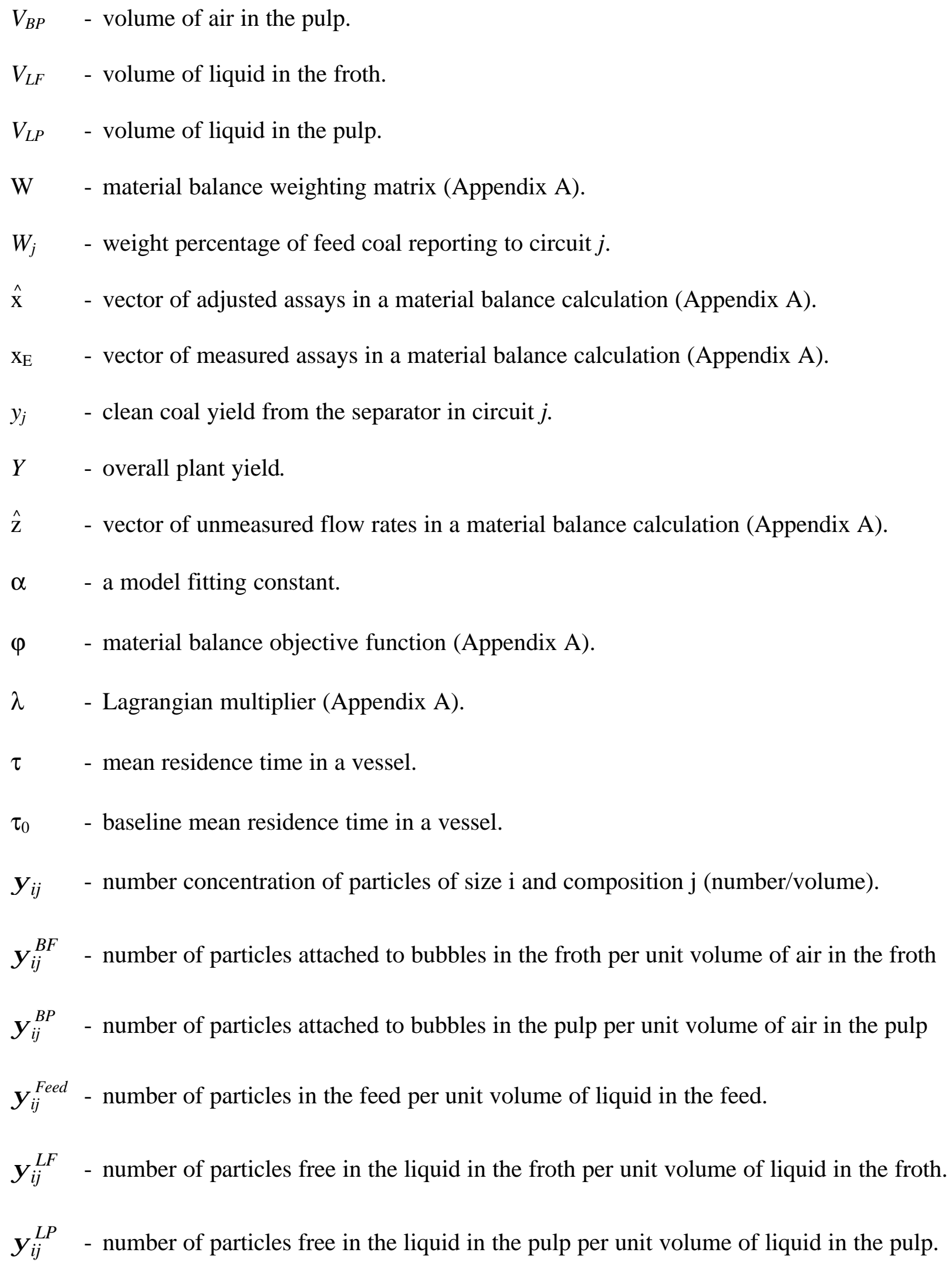


APPENDIX A

Material Balance Procedure 
The variables used to close the mass balance are shown in Figure A1. The mass balance equations required for this procedure include:

Pulp Mass Flowrate:

$$
M_{F}=M_{C}+M_{T}
$$

Solids Mass Flowrate:

$$
M_{F} p_{F}=M_{C} p_{C}+M_{T} p_{T}
$$

Global Ash Content Flowrate:

$$
M_{F} p_{F} A_{F}=M_{C} p_{C} A_{C}+M_{T} p_{T} A_{T}
$$

Size Mass Flowrate:

$$
M_{F} p_{F} f_{F, l}=M_{C} p_{C} f_{C, l}+M_{T} p_{T} f_{T, l}
$$

Ash Content per Size Flowrate:

$$
M_{F} p_{F} f_{F, l} A_{F, l}^{d}=M_{C} p_{C} f_{C, l} A_{C, l}^{d}+M_{T} p_{T} f_{T, l} A_{T, l}^{d}
$$

Particle Composition per Size Flowrate:

$$
M_{F} p_{F} f_{F, l} f_{F, k}^{d}=M_{C} p_{C} f_{C, l} f_{C, k}^{d}+M_{T} p_{T} f_{T, l} f_{T, k}^{d}
$$

\section{Feed}

$$
\begin{array}{ll}
M_{F} & f_{F, l} \\
p_{F} & A_{F, l}^{d} \\
A_{F} & f_{F, k}^{d}
\end{array}
$$

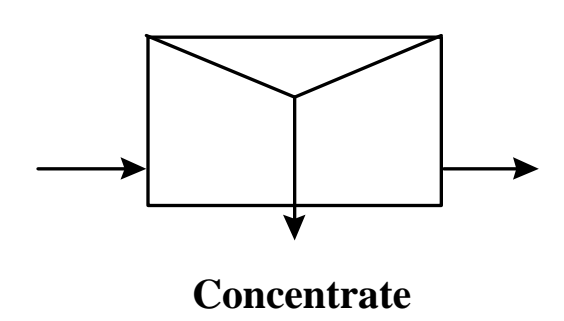

$M_{C} \quad$ Pulp mass flowrate

$p_{C} \quad$ Percent solids

$A_{C} \quad$ Ash content

$f_{C, l} \quad$ Size fraction of size $l$

$A_{C, l}^{d} \quad$ Ash content of size $l$

$f_{C, k}^{d} \quad$ Particle composition class $k$ per size $l$

\section{Tails}

$\begin{array}{ll}M_{T} & f_{T, l} \\ p_{T} & A_{T, l}^{d} \\ A_{T} & f_{T, k}^{d}\end{array}$

Figure A1. Flotation cell showing the variables used for the mass balance. 
The adjustment procedure minimizes an objective function based on the least squares criterion (note: $\mathbf{T}$ refers to matrix tranpose):

$$
\underset{\text { wrt } \hat{\mathbf{x}}, \hat{\mathbf{z}}}{\operatorname{minimize}} \phi=\frac{1}{2}\left(\mathbf{x}_{E}-\hat{\mathbf{x}}\right) \mathbf{W}\left(\mathbf{x}_{E}-\hat{\mathbf{x}}\right)^{\mathrm{T}}
$$

subject to the mass balance constraints (Equations A1-A6) of the form

$$
\mathbf{H}(\hat{\mathbf{x}}, \hat{\mathbf{z}})=\mathbf{0}
$$

where $\mathbf{x}_{E}$ are the measured values, $\hat{\mathbf{x}}$ the adjusted values, $\hat{\mathbf{z}}$ the unmeasured flowrates and $\mathbf{W}$ is a weighting matrix whose values are selected by the user to indicate the relative degree of confidence in each measured value.

A technique to minimize $\phi$ involves the use of Lagrangian multipliers to incorporate the mass balance constraints, i.e.:

$$
\underset{\text { wrt } \hat{\mathbf{x}}, \hat{\mathbf{z}}}{\operatorname{minimize}} \phi=\frac{1}{2}\left(\mathbf{x}_{E}-\hat{\mathbf{x}}\right) W\left(\mathbf{x}_{E}-\hat{\mathbf{x}}\right)^{\mathrm{T}}+\lambda \mathbf{H}(\hat{\mathbf{x}}, \hat{\mathbf{z}})
$$

where $\lambda$ are the Lagrangian multipliers.

The solution of Equation (A9) is nonlinear if $\hat{\mathbf{z}}$ is unknown and linear if $\hat{\mathbf{z}}$ is known. For unknown $\hat{\mathbf{z}}$ the objective function in Equation (A9) is decomposed into sublevels each with a linear solution and then a direct search for the value of $\hat{\mathbf{z}}$ that minimizes $\phi$ is performed. The following is a sample output from the material balance program. The Relative Standard Deviations shown in this output have been selected by the user and are directly related to the weighting matrix, $\mathbf{W}$. 


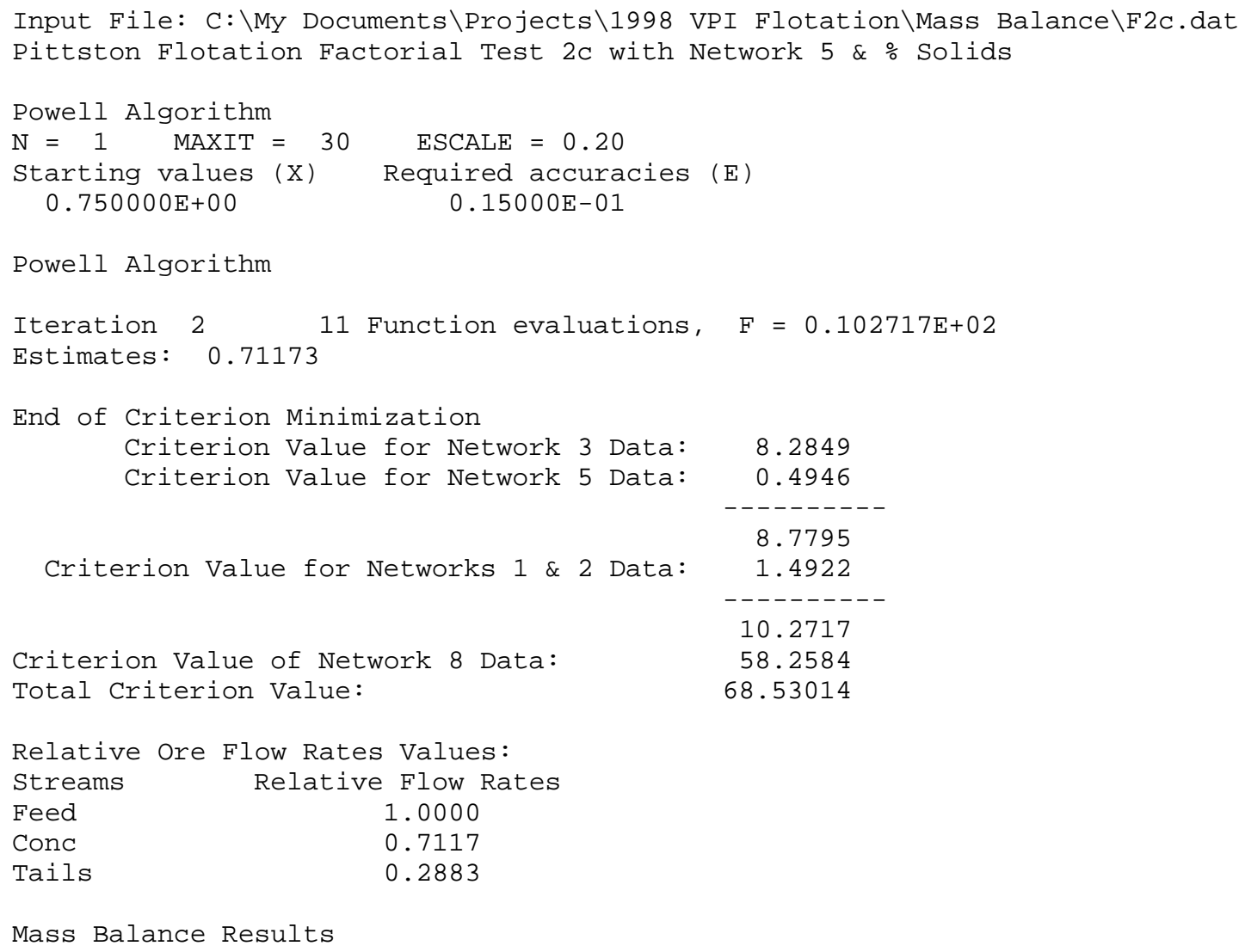

\section{Estimates of Networks 1 \& 2 variables}

\begin{tabular}{|c|c|c|c|c|c|c|c|c|}
\hline & $\mathrm{Pu}$ & Flow & ates & & Wat & er Flow & Rates & \\
\hline & Meas. & Estim. & Resid. & Relat. & Meas. & Estim. & Resid. & Relat. \\
\hline Streams & Values & Values & Values & St. Dev. & Values & Values & Values & St. Dev. \\
\hline Feed & 0.00 & 19.85 & 100.00 & 0.00 & 0.00 & 18.85 & 100.00 & 0.00 \\
\hline Conc & 0.00 & 4.45 & 100.00 & 0.00 & 0.00 & 3.74 & 100.00 & 0.00 \\
\hline Tails & 0.00 & 15.39 & 100.00 & 0.00 & 0.00 & 15.11 & 100.00 & 0.00 \\
\hline & So & id Flow & Rates & & $\mathrm{Pu}$ & Percen & t Solids & \\
\hline & Meas. & Estim. & Resid. & Relat. & Meas. & Estim. & Resid. & Relat. \\
\hline Streams & Values & Values & Values & St. Dev. & Values & Values & Values & St. Dev. \\
\hline Feed & 0.00 & 1.00 & 100.00 & 0.00 & 5.27 & 5.04 & 4.39 & 5.00 \\
\hline Conc & 0.00 & 0.71 & 100.00 & 0.00 & 15.81 & 15.98 & 1.10 & 5.00 \\
\hline Tails & 0.00 & 0.29 & 100.00 & 0.00 & 1.80 & 1.87 & 4.03 & 5.00 \\
\hline
\end{tabular}

\section{Estimates of Network 3 Mass Fractions}

\begin{tabular}{|c|c|c|c|c|c|c|c|c|}
\hline & \multicolumn{4}{|c|}{ Feed } & \multicolumn{4}{|c|}{ Conc } \\
\hline & Meas. & Estim. & Resid. & Relat. & Meas. & Estim. & Resid. & Relat. \\
\hline Streams & Values & Values & Values & St. Dev. & Values & Values & Values & St. Dev \\
\hline+200 & 30.10 & 33.04 & 9.78 & 5.00 & 49.20 & 46.43 & 5.64 & 5.00 \\
\hline $200 \times 400$ & 13.10 & 12.79 & 2.37 & 5.00 & 15.40 & 15.98 & 3.78 & 5.00 \\
\hline-400 & 56.80 & 54.17 & 4.64 & 5.00 & 35.40 & 37.59 & 6.19 & 5.00 \\
\hline \multicolumn{9}{|c|}{ Tails } \\
\hline Streams & $\begin{array}{l}\text { Meas. } \\
\text { Values }\end{array}$ & $\begin{array}{l}\text { Estim. } \\
\text { Values }\end{array}$ & $\begin{array}{l}\text { Resid. } \\
\text { Values }\end{array}$ & $\begin{array}{l}\text { Relat. } \\
\text { St.Dev. }\end{array}$ & $\begin{array}{l}\text { Meas. } \\
\text { Values }\end{array}$ & $\begin{array}{l}\text { Estim. } \\
\text { Values }\end{array}$ & $\begin{array}{l}\text { Resid. } \\
\text { Values }\end{array}$ & $\begin{array}{l}\text { Relat. } \\
\text { St.Dev }\end{array}$ \\
\hline+200 & 0.00 & 0.00 & 100.00 & 0.00 & & & & \\
\hline $200 \times 400$ & 4.90 & 4.91 & 0.14 & 5.00 & & & & \\
\hline-400 & 95.10 & 95.09 & 0.01 & 5.00 & & & & \\
\hline
\end{tabular}


$\underline{\text { Estimates of Network } 5 \text { Mass Fraction }}$

\begin{tabular}{|c|c|c|c|c|c|c|c|c|}
\hline \multirow[b]{3}{*}{ Streams } & \multicolumn{4}{|c|}{ Feed } & \multicolumn{4}{|c|}{ Conc } \\
\hline & Meas. & Estim. & Resid. & Relat. & Meas. & Estim. & Resid. & Relat. \\
\hline & Values & Values & Values & St. Dev. & Values & Values & Values & St.Dev. \\
\hline Ash Glob & 28.18 & 28.94 & 2.70 & 5.00 & 9.82 & 9.75 & 0.67 & 5.00 \\
\hline & & $\mathrm{Ta}$ & & & & & & \\
\hline & Meas. & Estim. & Resid. & Relat. & Meas. & Estim. & Resid. & Relat. \\
\hline Streams & Values & Values & Values & St. Dev. & Values & Values & Values & St. Dev. \\
\hline Ash Glob & 77.99 & 76.31 & 2.15 & 5.00 & & & & \\
\hline
\end{tabular}

Estimates of Network 8 MASS FRACTIONS

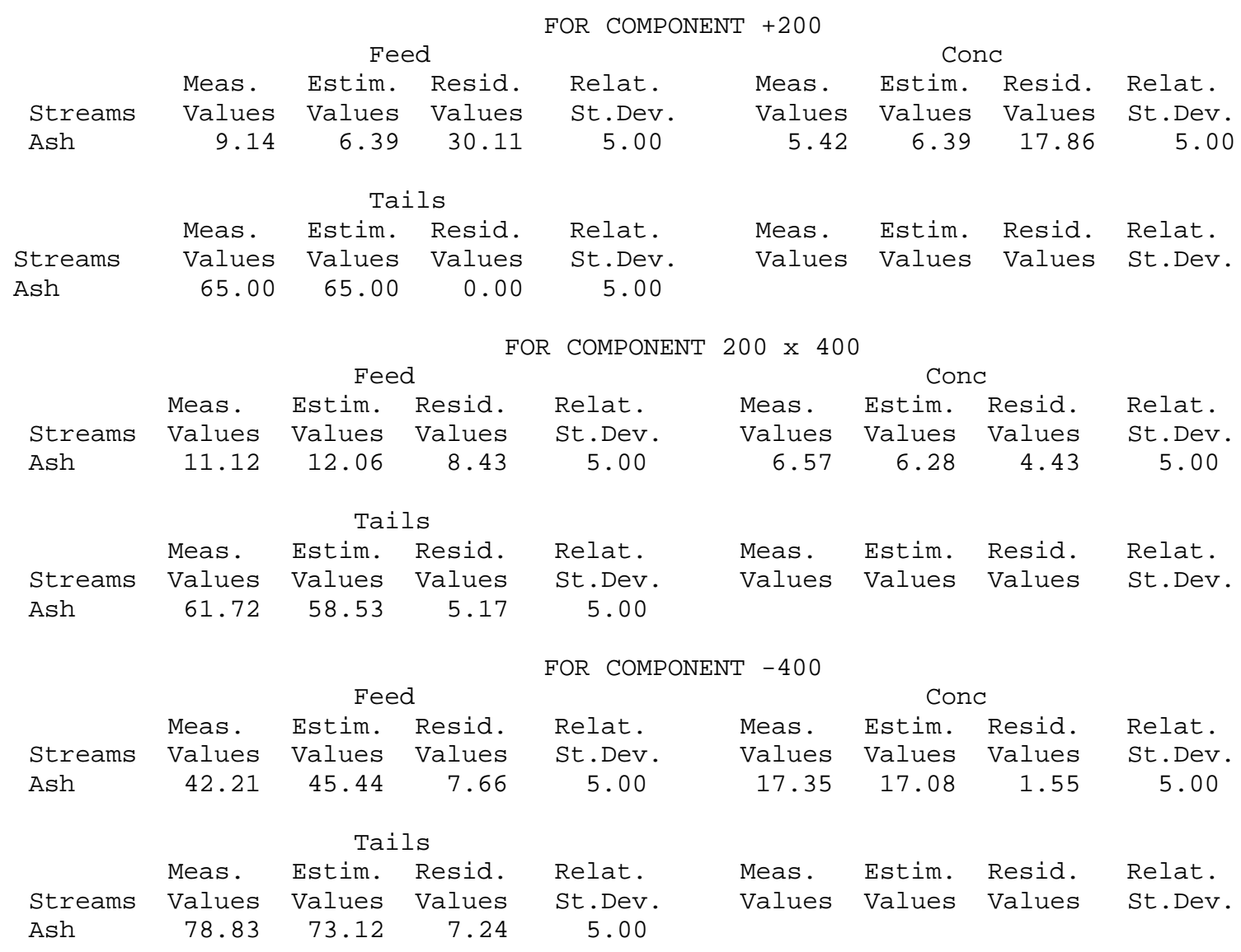




\section{APPENDIX B}

Raw Data from Audit of Pittston's Moss No. 3 Flotation Circuit 
Moss No. 3 Factorial Testing

Overall Analysis

\begin{tabular}{|c|c|c|c|c|c|c|c|c|c|c|c|c|}
\hline Test & \multicolumn{4}{|c|}{1} & \multicolumn{4}{|c|}{2} & \multicolumn{4}{|c|}{3} \\
\hline Feed \% Solids & \multicolumn{4}{|c|}{5.34} & \multicolumn{4}{|c|}{5.27} & \multicolumn{4}{|c|}{5.10} \\
\hline Feed \% Ash & \multicolumn{4}{|c|}{24.83} & \multicolumn{4}{|c|}{26.41} & \multicolumn{4}{|c|}{28.08} \\
\hline \multirow{2}{*}{ Time (min) } & \multicolumn{2}{|c|}{ Clean Coal } & \multicolumn{2}{|c|}{ Reject } & \multicolumn{2}{|c|}{ Clean Coal } & \multicolumn{2}{|c|}{$\begin{array}{c}\text { Reject } \\
\end{array}$} & \multicolumn{2}{|c|}{ Clean Coal } & \multicolumn{2}{|c|}{ Reject } \\
\hline & $\%$ Solids & $\%$ Ash & $\%$ Solids & $\%$ Ash & $\%$ Solids & $\%$ Ash & $\%$ Solids & $\%$ Ash & $\%$ Solids & $\%$ Ash & $\%$ Solids & $\%$ Ash \\
\hline 3 & 16.45 & 8.66 & \begin{tabular}{|l|}
1.61 \\
\end{tabular} & 83.91 & 16.43 & 9.46 & 1.76 & 76.97 & 16.02 & 9.48 & 1.82 & 77.00 \\
\hline 6 & 15.31 & 9.06 & 1.62 & 82.00 & 15.13 & 9.62 & 1.76 & 76.74 & 15.68 & 9.97 & 1.85 & 76.57 \\
\hline 12 & 16.28 & 8.60 & 1.74 & 75.67 & 14.95 & 9.48 & 1.81 & 77.36 & 15.71 & 9.78 & 1.89 & 76.21 \\
\hline 20 & 14.85 & 9.67 & 1.78 & 76.91 & 15.81 & 9.94 & 1.80 & 77.57 & 15.60 & 9.82 & 1.82 & 77.67 \\
\hline
\end{tabular}

\begin{tabular}{|c|c|c|c|c|c|c|c|c|c|c|c|c|}
\hline Test & \multicolumn{4}{|c|}{4} & \multicolumn{4}{|c|}{5} & \multicolumn{4}{|c|}{6} \\
\hline Feed $\%$ Solids & \multirow{2}{*}{\multicolumn{4}{|c|}{$\frac{5.28}{29.76}$}} & \multicolumn{4}{|c|}{5.11} & \multicolumn{4}{|c|}{5.07} \\
\hline Feed \% Ash & & & & & \multicolumn{4}{|c|}{22.35} & \multicolumn{4}{|c|}{32.79} \\
\hline \multirow{2}{*}{ Time (min) } & \multicolumn{2}{|c|}{ Clean Coal } & \multicolumn{2}{|c|}{$\begin{array}{c}\text { Reject } \\
\end{array}$} & \multicolumn{2}{|c|}{ Clean Coal } & \multicolumn{2}{|c|}{ Reject } & \multicolumn{2}{|c|}{ Clean Coal } & \multicolumn{2}{|c|}{ Reject } \\
\hline & $\%$ Solids & $\%$ Ash & $\%$ Solids & $\%$ Ash & $\%$ Solids & $\%$ Ash & $\%$ Solids & $\%$ Ash & $\%$ Solids & $\%$ Ash & $\%$ Solids & $\%$ Ash \\
\hline 3 & 17.12 & 9.20 & 1.97 & 74.79 & 16.62 & \begin{tabular}{|l|}
8.77 \\
\end{tabular} & \begin{tabular}{|l|}
1.62 \\
\end{tabular} & \begin{tabular}{|l|}
80.38 \\
\end{tabular} & 16.95 & 10.78 & 2.15 & 86.92 \\
\hline 6 & 18.64 & 8.56 & 1.95 & 76.32 & 16.20 & 8.65 & 1.58 & 78.78 & 17.21 & 10.99 & 2.18 & 86.22 \\
\hline 12 & 18.52 & 8.90 & 1.84 & 76.36 & 15.65 & 8.57 & 1.58 & 74.31 & 17.45 & 9.41 & 2.02 & 85.38 \\
\hline 20 & 18.33 & 8.67 & 1.92 & 78.54 & 15.99 & 8.17 & 1.50 & 73.17 & 18.05 & 9.56 & 1.98 & 85.78 \\
\hline
\end{tabular}

\begin{tabular}{|c|c|c|c|c|c|c|c|c|c|c|c|c|}
\hline Test & \multicolumn{4}{|c|}{7} & \multicolumn{4}{|c|}{8} & \multicolumn{4}{|c|}{9} \\
\hline Feed $\%$ Solids & \multicolumn{4}{|c|}{5.54} & \multicolumn{4}{|c|}{5.28} & \multicolumn{4}{|c|}{5.49} \\
\hline Feed \% Ash & \multicolumn{4}{|c|}{32.46} & \multicolumn{4}{|c|}{35.71} & \multicolumn{4}{|c|}{33.77} \\
\hline \multirow{2}{*}{ Time (min) } & \multicolumn{2}{|c|}{ Clean Coal } & \multicolumn{2}{|c|}{ Reject } & \multicolumn{2}{|c|}{ Clean Coal } & \multicolumn{2}{|c|}{ Reject } & \multicolumn{2}{|c|}{ Clean Coal } & \multicolumn{2}{|c|}{ Reject } \\
\hline & $\%$ Solids & $\%$ Ash & $\%$ Solids & $\%$ Ash & $\%$ Solids & $\%$ Ash & $\%$ Solids & $\%$ Ash & $\%$ Solids & $\%$ Ash & $\%$ Solids & $\%$ Ash \\
\hline 3 & 18.66 & 9.28 & 1.92 & 82.31 & 18.21 & 9.86 & 2.06 & 85.68 & 16.59 & 10.87 & 2.19 & 84.14 \\
\hline 6 & 18.88 & 8.82 & 1.90 & 82.57 & 18.68 & 9.60 & 2.03 & 86.46 & 16.32 & 11.56 & 2.24 & 83.45 \\
\hline 12 & 18.96 & 9.18 & 1.94 & 82.22 & 18.07 & 9.97 & 2.05 & 85.86 & 14.79 & 12.72 & 2.30 & 83.64 \\
\hline 20 & 18.57 & 9.79 & 2.12 & 83.79 & 17.86 & 10.70 & 2.11 & 85.87 & 14.86 & 12.13 & 2.31 & 83.07 \\
\hline
\end{tabular}

\begin{tabular}{|c|c|c|c|c|c|c|c|c|c|c|c|c|}
\hline Test & \multicolumn{4}{|c|}{10} & \multicolumn{4}{|c|}{ Baseline Sample (Day 1) } & \multicolumn{4}{|c|}{ Baseline Sample (Day 2) } \\
\hline Feed \% Solids & \multicolumn{4}{|c|}{5.72} & \multirow{2}{*}{\multicolumn{4}{|c|}{$\begin{array}{c}5.19 \\
2933\end{array}$}} & \multicolumn{4}{|c|}{4.74} \\
\hline Feed \% Ash & \multicolumn{4}{|c|}{31.23} & & & & & \multicolumn{4}{|c|}{35.13} \\
\hline \multirow{2}{*}{ Time (min) } & \multicolumn{2}{|c|}{ Clean Coal } & \multicolumn{2}{|c|}{ Reject } & \multicolumn{2}{|c|}{ Clean Coal } & \multicolumn{2}{|c|}{ Reject } & \multicolumn{2}{|c|}{ Clean Coal } & \multicolumn{2}{|c|}{ Reject } \\
\hline & $\%$ Solids & $\%$ Ash & $\%$ Solids & $\%$ Ash & $\%$ Solids & $\%$ Ash & $\%$ Solids & $\%$ Ash & $\%$ Solids & $\%$ Ash & $\%$ Solids & $\%$ Ash \\
\hline 3 & 16.67 & 11.47 & 2.26 & 84.47 & $-N A-$ & -NA- & -NA- & -NA- & -NA- & -NA- & $-\mathrm{NA}-$ & -NA- \\
\hline 6 & 16.27 & 11.04 & 2.22 & 83.91 & -NA- & -NA- & -NA- & $-N A-$ & -NA- & -NA- & -NA- & -NA- \\
\hline 12 & -NA- & -NA- & $-N A-$ & $-\mathrm{NA}-$ & -NA- & $-\mathrm{NA}-$ & $-N A-$ & $-N A-$ & $-N A-$ & $-N A-$ & $-N A-$ & $-\mathrm{NA}-$ \\
\hline 20 & 16.24 & 11.04 & 2.17 & 83.33 & 17.41 & 9.39 & 1.95 & 78.76 & 17.24 & 10.04 & 2.01 & 85.39 \\
\hline
\end{tabular}


Moss No. 3 Factorial Testing

Size-by-Size Analysis of 20 Minute Samples

\begin{tabular}{|c|c|c|c|c|c|c|c|c|c|c|c|}
\hline \multirow[b]{2}{*}{ Stream } & \multirow[b]{2}{*}{ Size (mesh) } & \multicolumn{2}{|c|}{ Test 1 (20 min) } & \multicolumn{2}{|c|}{ Test $2(20 \mathrm{~min})$} & \multicolumn{2}{|c|}{ Test $3(20 \mathrm{~min})$} & \multicolumn{2}{|c|}{ Test $4(20 \mathrm{~min})$} & \multicolumn{2}{|c|}{ Test $5(20 \mathrm{~min})$} \\
\hline & & $\%$ Weight & $\%$ Ash & $\%$ Weight & $\%$ Ash & $\%$ Weight & $\%$ Ash & $\%$ Weight & $\%$ Ash & $\%$ Weight & $\%$ Ash \\
\hline \multirow[t]{4}{*}{ Feed } & +200 & 31.3 & 5.03 & 30.1 & 6.65 & 27.6 & 5.52 & 31.0 & 6.01 & 36.7 & 5.05 \\
\hline & $200 \times 400$ & 14.6 & 14.36 & 13.1 & 11.12 & 13.8 & 11.24 & 12.6 & 12.03 & 13.4 & 10.84 \\
\hline & -400 & 54.1 & 41.33 & 56.8 & 42.21 & 58.6 & 41.45 & 56.4 & 47.56 & 49.9 & 36.80 \\
\hline & & & & & & & & & & & \\
\hline \multirow[t]{7}{*}{ Clean Coal } & +100 & 28.0 & 4.75 & 22.4 & 4.77 & 19.0 & 3.75 & -NA- & -NA- & 26.6 & 3.29 \\
\hline & $100 \times 150$ & 12.8 & 5.91 & 10.2 & 4.49 & 10.0 & 3.47 & -NA- & -NA- & 11.9 & 3.93 \\
\hline & $150 \times 200$ & 9.6 & 5.98 & 16.6 & 6.88 & 10.3 & 4.20 & -NA- & -NA- & 10.4 & 4.87 \\
\hline & $200 \times 270$ & 8.0 & 6.86 & 8.2 & 6.14 & 10.4 & 5.40 & -NA- & -NA- & 8.5 & 6.06 \\
\hline & $270 \times 400$ & 8.5 & 9.21 & 7.2 & 7.06 & 7.0 & 5.81 & -NA- & -NA- & 7.2 & 7.40 \\
\hline & -400 & 33.1 & 17.66 & 35.4 & 17.35 & 43.3 & 15.64 & -NA- & -NA- & 35.4 & 14.82 \\
\hline & & & & & & & & & & & \\
\hline \multirow[t]{2}{*}{ Reject } & +400 & 4.8 & 61.77 & 4.9 & 61.72 & 8.8 & 55.74 & 9.5 & 61.54 & 7.1 & 48.65 \\
\hline & -400 & 95.2 & 78.47 & 95.1 & 78.83 & 91.2 & 78.48 & 90.5 & 81.9 & 92.9 & 74.19 \\
\hline
\end{tabular}

\begin{tabular}{|c|c|c|c|c|c|c|c|c|c|c|c|}
\hline \multirow{2}{*}{ Stream } & \multirow{2}{*}{ Size (mesh) } & \multicolumn{2}{|c|}{ Test $6(20 \mathrm{~min})$} & \multicolumn{2}{|c|}{ Test 7 (20 min) } & \multicolumn{2}{|c|}{ Test 8 (20 min) } & \multicolumn{2}{|c|}{ Test $9(20 \mathrm{~min})$} & \multicolumn{2}{|c|}{ Test $10(20 \mathrm{~min})$} \\
\hline & & $\%$ Weight & $\%$ Ash & $\%$ Weight & $\%$ Ash & $\%$ Weight & $\%$ Ash & $\%$ Weight & $\%$ Ash & $\%$ Weight & $\%$ Ash \\
\hline \multirow[t]{3}{*}{ Feed } & +200 & 30.9 & 4.17 & 29.7 & 5.14 & 25.4 & 4.63 & 29.2 & 6.91 & 31.2 & 6.55 \\
\hline & $200 \times 400$ & 16.9 & 17.12 & 12.5 & 14.4 & 16.7 & 21.84 & 14.4 & 16.93 & 11.4 & 12.83 \\
\hline & -400 & 52.2 & 54.00 & 57.8 & 55.24 & 57.9 & 54.59 & 56.4 & 50.46 & 57.4 & 50.10 \\
\hline \multirow{6}{*}{ Clean Coal } & +100 & 35.5 & 3.98 & 19.7 & 3.15 & 26.4 & 3.12 & 24.7 & 3.57 & 28.2 & 3.89 \\
\hline & $100 \times 150$ & 7.3 & 4.88 & 10.5 & 4.43 & 11.2 & 4.22 & 10.1 & 4.6 & 14.2 & 6.83 \\
\hline & $150 \times 200$ & 4.0 & 5.79 & 10.1 & 7.06 & 8.8 & 6.06 & 10.8 & 7.05 & 8.2 & 5.69 \\
\hline & $200 \times 270$ & 3.1 & 6.74 & 5.8 & 6.76 & 8.5 & 6.62 & 6.5 & 7.09 & 7.8 & 7.31 \\
\hline & $270 \times 400$ & 1.8 & 7.36 & 3.8 & 7.75 & 7.6 & 7.92 & 8.2 & 9.07 & 5.9 & 8.00 \\
\hline & -400 & 48.3 & 15.96 & 50.1 & 15.76 & 37.5 & 19.61 & 39.7 & 22.63 & 35.7 & 21.49 \\
\hline \multirow[t]{2}{*}{ Reject } & +400 & 5.2 & 68.33 & 6.7 & 60.68 & 4.4 & 70.88 & 4.8 & 69.45 & 5.5 & 67.99 \\
\hline & -400 & 94.8 & 86.74 & 93.3 & 85.64 & 95.6 & 87.20 & 95.2 & 84.71 & 94.5 & 84.58 \\
\hline
\end{tabular}


Moss No. 3 Factorial Testing

Size-by-Size Compositional Analysis of 20 Minute Samples

\begin{tabular}{|c|c|c|c|c|c|c|c|c|c|c|c|c|c|c|c|}
\hline & \multicolumn{5}{|c|}{ Test $1(20 \mathrm{~min})$} & \multirow{2}{*}{\multicolumn{5}{|c|}{ Test $2(20 \mathrm{~min})$}} & \multirow{2}{*}{\multicolumn{5}{|c|}{ 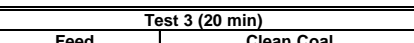 }} \\
\hline & & ed & . & Clean Coal & & & ed & & & & & & & & \\
\hline $\begin{array}{l}\text { Slze (Mesn) } \\
\text { Composition }\end{array}$ & +200 & $200 \times 400$ & +100 & $150 \times 200$ & $270 \times 400$ & +200 & $200 \times 400$ & +100 & $150 \times 200$ & $270 \times 400$ & +200 & $200 \times 400$ & +100 & $150 \times 200$ & $270 \times 400$ \\
\hline $\begin{array}{l}\text { Composition } \\
\text { \%ineral Matter }\end{array}$ & & & & & & & & & & & & & & & \\
\hline & 18.1 & 25.5 & 13.7 & 18.4 & 18.6 & 21.4 & 27.1 & 13.4 & 23. & 29. & 23.3 & 35.5 & 16. & 18.8 & 28.3 \\
\hline $0-10$ & $\frac{71.5}{71.5}$ & 52.7 & $\frac{73.1}{77.1}$ & 65.8 & $\frac{61.6}{61.6}$ & 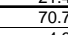 & 54.1 & 80.4 & 67.2 & 56. & $\frac{25.5}{71.5}$ & 47.9 & 78. & 69.6 & 56.2 \\
\hline $10-20$ & 5.8 & 5.2 & 5.8 & 8.1 & 7.2. & 4.3 & 5.2 & 4.5 & 4.8 & 6. & 2.9 & 5.1 & 3. & 5.0 & 6. \\
\hline $20-30$ & 1.4 & 3.3 & 2.0 & 2.9 & 2.8 & 1.4 & 2.5 & 0.9 & 1.5 & 1. & 0.7 & 1.2 & 1.5 & 3.4 & \\
\hline & 1.2. & 1.2 & 0.4 & 1.2 & 1.6 & 0.4 & 1.3 & 0.3 & 0.7 & 1. & 0.2 & 0.9 & 0. & 1.1 & 1. \\
\hline$\frac{40-50}{50-60}$ & 0.1 & 0.9 & 0.4 & $\frac{1.1}{0.6}$ & 1.4 & 0.2 & 1.0 & 0.2 & 0.5 & 1. & $\frac{0.4}{0.5}$ & 0.7 & 0.4 & 0.6 & \\
\hline $60-70$ & 0.6 & 02 & 02 & 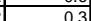 & 34 & 02 & $\frac{0.02}{02}$ & 01 & 0 & 0 & 0 & $\frac{1.1}{11}$ & 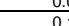 & $\frac{0.3}{0.4}$ & $\frac{0.8}{0.6} \cdot 3-10$ \\
\hline & 02 & 07 & 00 & 0.5 & 06 & 03 & 0.4 & 00 & 0 & 0 & 0.1 & 0.8 & 0 & 0.0 & 0.6 \\
\hline 80 & 0.3 & 0.8 & 0.1 & 0.5 & 0.7 & 0.1 & 0.6 & 0.0 & 0. & 0.1 & 0.0 & 1.0 & 0.9 & 0.3 & $\frac{0.0}{0.6}$ \\
\hline$\frac{90-100}{100}$ & 0.3 & $\frac{6.8}{19}$ & 0.1 & 0.6 & 3.0 & 0.5 & $\frac{5.4}{15}$ & 0.1 & 0.4 & 2.9 & 0.5 & 4.9 & 0.4 & 0.5 & 2.4 \\
\hline
\end{tabular}

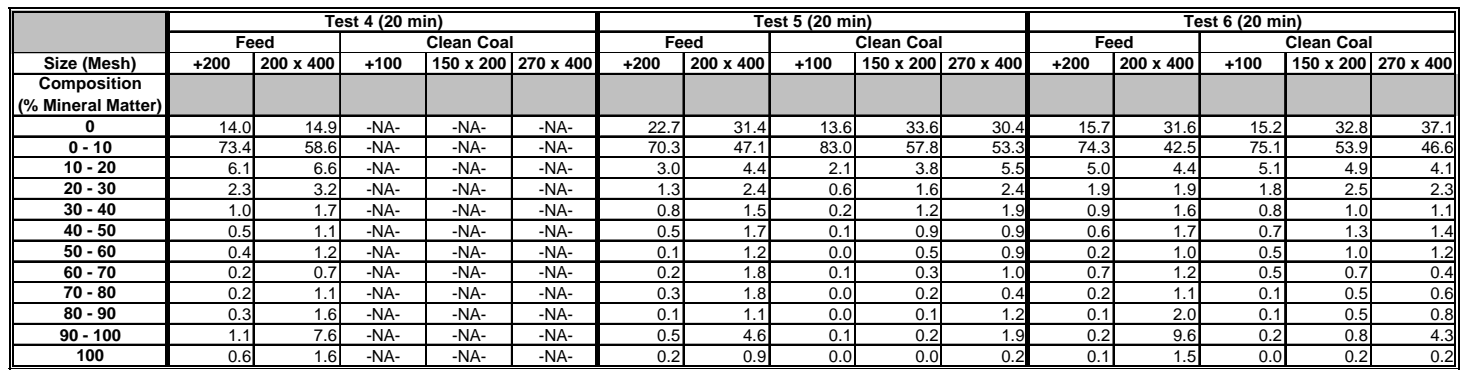

\begin{tabular}{|c|c|c|c|c|c|c|c|c|c|c|c|c|c|c|c|}
\hline & \multicolumn{5}{|c|}{ Test $7(20 \mathrm{~min})$} & \multicolumn{5}{|c|}{ Test $8(20 \mathrm{~min})$} & \multicolumn{5}{|c|}{$\begin{array}{l}\text { Test } 9(20 \mathrm{~min}) \\
\end{array}$} \\
\hline & \multicolumn{2}{|c|}{ Feed } & \multicolumn{3}{|c|}{ Clean Coal } & \multicolumn{2}{|c|}{ Feed } & \multicolumn{3}{|c|}{ Clean Coal } & \multicolumn{2}{|c|}{ Feed } & \multicolumn{3}{|c|}{ Clean Coal } \\
\hline Size (Mesh) & +200 & $200 \times 400$ & +100 & $150 \times 200$ & $270 \times 400$ & +200 & $200 \times 400$ & +100 & $150 \times 200$ & $270 \times 400$ & +200 & $200 \times 400$ & +100 & $150 \times 200$ & $270 \times 400$ \\
\hline $\begin{array}{c}\text { Composition } \\
\text { (\% Mineral Matter) }\end{array}$ & & & & & & & & & & & & & & & \\
\hline 0 & 11.4 & 24.6 & 10.5 & 24.3 & 41.8 & 20.2 & 29.0 & 15.9 & 17.4 & 30.9 & 14.7 & 17.3 & 9.0 & 14.3 & 31.3 \\
\hline $0-10$ & 77.1 & 47.7 & 85.0 & 61.8 & 42.8 & 69.2 & 43.8 & 80.0 & 66.4 & 53.7 & 73.5 & 54.7 & 83.3 & 68.1 & 49.3 \\
\hline $10-20$ & 6.1 & 6.5 & 2.7 & 5.0 & $\begin{array}{cl}5.1 \\
\end{array}$ & 5.0 & 4.4 & 2.6 & 6.2 & 4.5 & 5.1 & 5.5 & 5.3 & 5.4 & 5.0 \\
\hline $20-30$ & 1.6 & 2.0 & 0.7 & 2.6 & 2.0 & 1.1 & 1.5 & 1.0 & 3.5 & 1.9 & 2.3 & 3.6 & 0.9 & 3.2 & 3.2 \\
\hline $30-40$ & 0.9 & 1.8 & 0.5 & 2.4 & 2.1 & 1.0 & 1.6 & 0.2 & 2.3 & 1.5 & 1.6 & 2.8 & 0.8 & 2.5 & 2.0 \\
\hline $40-50$ & 0.5 & 1.7 & 0.3 & 0.6 & 1.3 & 0.7 & 1.9 & 0.0 & 1.2 & 1.6 & 0.7 & 1.4 & 0.1 & 2.1 & 0.7 \\
\hline $50-60$ & 0.4 & 2.0 & 0.3 & 0.8 & 0.8 & 0.5 & 0.8 & 0.1 & 0.5 & 0.9 & 0.5 & 1.2 & 0.1 & 1.1 & 1.7 \\
\hline $60-70$ & 0.5 & 1.0 & 0.0 & 0.4 & 0.6 & 0.3 & 1.1 & 0.1 & 0.6 & 1.4 & 0.3 & 1.2 & 0.1 & 0.6 & 1.3 \\
\hline $70-80$ & 0.0 & 0.9 & 0.0 & 0.7 & 0.7 & 0.5 & 1.2 & 0.1 & 0.8 & 0.6 & 0.3 & 1.0 & 0.2 & 0.6 & 1.1 \\
\hline $80-90$ & 0.6 & 1.2 & 0.0 & 0.7 & 0.6 & 0.1 & 1.1 & 0.0 & 0.1 & 1.1 & 0.3 & 1.5 & 0.0 & 0.9 & 1.1 \\
\hline $90-100$ & 0.3 & 8.7 & 0.0 & 0.6 & 2.1 & 1.2 & 11.9 & 0.1 & 0.9 & 1.6 & \begin{tabular}{l|l}
0.3 \\
\end{tabular} & \begin{tabular}{l|l|}
8.3 \\
\end{tabular} & 0.1 & 1.0 & 2.7 \\
\hline 100 & 0.3 & 1.9 & 0.0 & 0.1 & 0.1 & 0.3 & 1.7 & 0.0 & 0.1 & 0.2 & 0.4 & $\begin{array}{l}1.7 \\
\end{array}$ & 0.0 & 0.3 & 0.4 \\
\hline
\end{tabular}

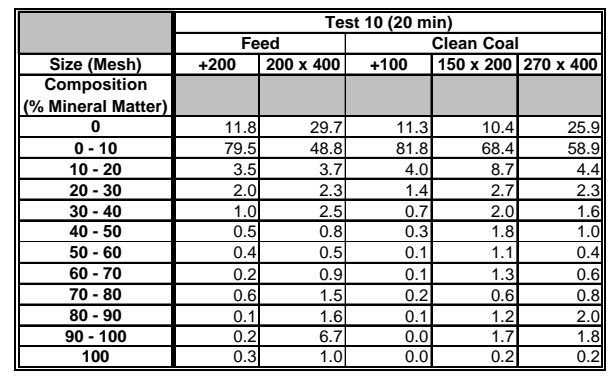


Moss No. 3 Disturbance Testing Batch Flotation Data

\begin{tabular}{||c|r|r|r|r||}
\hline Collection & \multicolumn{2}{|c|}{ Clean Coal } & \multicolumn{2}{c|}{ Reject } \\
\cline { 2 - 5 } Time (min) & Weight (g) & \% Ash & Weight (g) & $\%$ Ash \\
\hline $\mathbf{0}$ & 143.6 & 6.59 & 68.1 & 71.00 \\
\hline $\mathbf{4}$ & 83.2 & 5.15 & 119.6 & 41.86 \\
\hline $\mathbf{8}$ & 139.5 & 3.27 & 73.5 & 66.08 \\
\hline $\mathbf{1 2}$ & 155.8 & 6.78 & 67.1 & 74.27 \\
\hline $\mathbf{1 6}$ & 94.8 & 5.46 & 125.4 & 40.29 \\
\hline $\mathbf{2 4}$ & 136.3 & 6.11 & 66.9 & 65.72 \\
\hline $\mathbf{3 2}$ & 145.4 & 6.41 & 61.3 & 72.32 \\
\hline $\mathbf{6 4}$ & 145.5 & 6.88 & 65.3 & 75.97 \\
\hline $\mathbf{1 2 8}$ & 155.6 & 6.75 & 79.3 & 73.60 \\
\hline $\mathbf{2 5 6}$ & 148.4 & 7.75 & 82.5 & 81.02 \\
\hline $\mathbf{5 1 2}$ & 128.6 & 8.03 & 61.2 & 83.51 \\
\hline
\end{tabular}


Moss No. 3 Disturbance Testing Release Analysis Data

\begin{tabular}{||r|r|r|r|r|r|r|r||}
\hline \hline Sample & Weight (g) & \% Weight & \% Ash & $\begin{array}{c}\text { Cumulative } \\
\text { \% Ash }\end{array}$ & \% Yield & $\begin{array}{c}\text { \% Combustible } \\
\text { Recovery }\end{array}$ & $\begin{array}{c}\text { \% Ash } \\
\text { Rejection }\end{array}$ \\
\hline Float 4 & 6.4 & 3.4 & 2.52 & 2.5 & 3.4 & 4.5 & 99.7 \\
\hline Tail 4 & 75.1 & 39.9 & 3.10 & 3.1 & 43.3 & 56.4 & 94.8 \\
\hline Tail 3 & 42.1 & 22.3 & 5.16 & 3.8 & 65.6 & 84.9 & 90.3 \\
\hline Tail 2 & 19.6 & 10.4 & 17.84 & 5.7 & 76.0 & 96.3 & 83.1 \\
\hline Tail 1 & 11.8 & 6.3 & 81.70 & 11.5 & 82.3 & 97.9 & 63.1 \\
\hline Tail & 33.4 & 17.7 & 91.11 & 25.6 & 100.0 & 100.0 & 0.0 \\
\hline Total & 188.4 & 100.0 & 25.60 & \multicolumn{3}{|c|}{} \\
\hline
\end{tabular}

\begin{tabular}{||r|r|r|r|r|r|r|r||}
\hline \multicolumn{7}{|c|}{ 24 Minute Sample } \\
\hline Sample & Weight (g) & \% Weight & \% Ash & $\begin{array}{c}\text { Cumulative } \\
\text { \% Ash }\end{array}$ & \% Yield & $\begin{array}{c}\text { \% Combustible } \\
\text { Recovery }\end{array}$ & $\begin{array}{c}\text { \% Ash } \\
\text { Rejection }\end{array}$ \\
\hline Float 4 & 120.0 & 61.8 & 3.20 & 3.2 & 61.8 & 79.6 & 92.1 \\
\hline Tail 4 & 4.2 & 2.2 & 6.90 & 3.3 & 63.9 & 82.3 & 91.5 \\
\hline Tail 3 & 11.5 & 5.9 & 11.27 & 4.0 & 69.8 & 89.3 & 88.8 \\
\hline Tail 2 & 16.1 & 8.3 & 29.13 & 6.7 & 78.1 & 97.1 & 79.1 \\
\hline Tail 1 & 10.3 & 5.3 & 85.28 & 11.7 & 83.4 & 98.1 & 60.9 \\
\hline Tail & 32.2 & 16.6 & 91.46 & 24.9 & 100.0 & 100.0 & 0.0 \\
\hline Total & 194.3 & 100.0 & 24.88 & \multicolumn{7}{|c|}{} \\
\hline
\end{tabular}

\begin{tabular}{||r|r|r|r|r|r|r|r||}
\hline Sample & Weight (g) & \% Weight & \% Ash & $\begin{array}{c}\text { Cumulative } \\
\text { \% Ash }\end{array}$ & \% Yield & $\begin{array}{c}\text { \% Combustible } \\
\text { Recovery }\end{array}$ & $\begin{array}{c}\text { \% Ash } \\
\text { Rejection }\end{array}$ \\
\hline Float 4 & 59.4 & 31.0 & 2.92 & 2.9 & 31.0 & 41.6 & 96.7 \\
\hline Tail 4 & 8.2 & 4.3 & 4.63 & 3.1 & 35.3 & 47.2 & 96.0 \\
\hline Tail 3 & 39.6 & 20.7 & 5.29 & 3.9 & 55.9 & 74.2 & 92.1 \\
\hline Tail 2 & 34.6 & 18.0 & 15.69 & 6.8 & 74.0 & 95.3 & 81.8 \\
\hline Tail 1 & 14.9 & 7.8 & 78.66 & 13.6 & 81.7 & 97.6 & 59.7 \\
\hline Tail & 35.0 & 18.3 & 90.35 & 27.6 & 100.0 & 100.0 & 0.0 \\
\hline Total & 191.7 & 100.0 & 27.64 & & & & \\
\hline
\end{tabular}

\begin{tabular}{||r|r|r|r|r|r|r|r||}
\hline \hline Sample & Weight (g) & \% Weight & \% Ash & $\begin{array}{c}\text { Cumulative } \\
\text { \% Ash }\end{array}$ & \% Yield & $\begin{array}{c}\text { \% Combustible } \\
\text { Recovery }\end{array}$ & $\begin{array}{c}\text { \% Ash } \\
\text { Rejection }\end{array}$ \\
\hline Float 4 & 132.0 & 76.6 & 3.63 & 3.6 & 76.6 & 92.6 & 86.3 \\
\hline Tail 4 & 5.1 & 3.0 & 17.62 & 4.2 & 79.6 & 95.6 & 83.7 \\
\hline Tail 3 & 3.5 & 2.0 & 41.47 & 5.1 & 81.6 & 97.1 & 79.5 \\
\hline Tail 2 & 1.4 & 0.8 & 78.54 & 5.8 & 82.4 & 97.3 & 76.4 \\
\hline Tail 1 & 6.2 & 3.6 & 87.46 & 9.2 & 86.0 & 97.9 & 60.8 \\
\hline Tail & 24.1 & 14.0 & 87.99 & 20.2 & 100.0 & 100.0 & 0.0 \\
\hline Total & 172.3 & 100.0 & 20.24 & \multicolumn{7}{|c|}{} \\
\hline
\end{tabular}

\begin{tabular}{||r|r|r|r|r|r|r|r||}
\hline \hline Sample & Weight (g) & \% Weight & \% Ash & $\begin{array}{c}\text { Cumulative } \\
\text { \% Ash }\end{array}$ & \% Yield & $\begin{array}{c}\text { \% Combustible } \\
\text { Recovery }\end{array}$ & $\begin{array}{c}\text { \% Ash } \\
\text { Rejection }\end{array}$ \\
\hline Float 4 & 129.3 & 61.0 & 3.49 & 3.5 & 61.0 & 87.7 & 93.5 \\
\hline Tail 4 & 9.2 & 4.3 & 13.41 & 4.1 & 65.4 & 93.3 & 91.7 \\
\hline Tail 3 & 4.8 & 2.3 & 32.36 & 5.1 & 67.7 & 95.5 & 89.5 \\
\hline Tail 2 & 5.0 & 2.4 & 73.38 & 7.4 & 70.0 & 96.5 & 84.2 \\
\hline Tail 1 & 15.0 & 7.1 & 89.92 & 15.0 & 77.1 & 97.5 & 64.8 \\
\hline Tail & 48.5 & 22.9 & 92.77 & 32.8 & 100.0 & 100.0 & 0.0 \\
\hline Total & 211.8 & 100.0 & 32.79 & \multicolumn{7}{|c|}{} \\
\hline
\end{tabular}




\section{Residence Time Distribution Testing}

\begin{tabular}{|c|c|}
\hline Time (min) & Lithium Concentration (mg/l) \\
\hline 0.0 & 0.06 \\
\hline 0.5 & 0.06 \\
\hline 1.0 & 0.39 \\
\hline 1.5 & 1.81 \\
\hline 2.0 & 3.02 \\
\hline 2.5 & $\overline{4.04}$ \\
\hline 3.0 & 5.02 \\
\hline 3.5 & 4.46 \\
\hline 4.0 & 3.28 \\
\hline 4.5 & 2.58 \\
\hline 5.0 & 2.18 \\
\hline 5.5 & 1.59 \\
\hline 6.0 & 1.27 \\
\hline 6.5 & 0.99 \\
\hline 7.0 & 0.77 \\
\hline 7.5 & 0.68 \\
\hline 8.0 & 0.68 \\
\hline 8.5 & 0.57 \\
\hline 9.0 & 0.52 \\
\hline 9.5 & 0.51 \\
\hline 10.0 & 0.50 \\
\hline 11.0 & 0.45 \\
\hline 12.0 & 0.40 \\
\hline
\end{tabular}




\section{APPENDIX C}

Video Sensor Calibration Data 
Video Sensor Calibration

\begin{tabular}{|r|r|r|}
\hline Gray Level & \% Ash & \multicolumn{1}{c|}{ Date } \\
\hline 113.26 & 84.63 & $6 / 7 / 98$ \\
\hline 113.34 & 83.95 & $6 / 7 / 98$ \\
\hline 113.02 & 83.61 & $6 / 7 / 98$ \\
\hline 113.78 & 83.48 & $6 / 7 / 98$ \\
\hline 114.25 & 84.05 & $6 / 7 / 98$ \\
\hline 114.92 & 83.59 & $6 / 7 / 98$ \\
\hline 117.14 & 84.47 & $6 / 7 / 98$ \\
\hline 121.83 & 84.52 & $6 / 10 / 98$ \\
\hline 121.81 & 86.17 & $6 / 10 / 98$ \\
\hline 95.17 & 78.64 & $6 / 10 / 98$ \\
\hline 112.21 & 81.07 & $6 / 10 / 98$ \\
\hline 110.46 & 80.27 & $6 / 11 / 98$ \\
\hline 118.67 & 84.2 & $6 / 11 / 98$ \\
\hline 117.11 & 82.05 & $6 / 11 / 98$ \\
\hline 120.53 & 84.38 & $6 / 11 / 98$ \\
\hline 118.76 & 83.81 & $6 / 11 / 98$ \\
\hline 116.29 & 82.66 & $6 / 15 / 98$ \\
\hline 116.60 & 83.69 & $6 / 15 / 98$ \\
\hline 116.81 & 84.06 & $6 / 15 / 98$ \\
\hline 117.12 & 84.8 & $6 / 15 / 98$ \\
\hline 121.63 & 86.84 & $6 / 19 / 98$ \\
\hline 121.94 & 87.09 & $6 / 19 / 98$ \\
\hline 120.67 & 86.86 & $6 / 19 / 98$ \\
\hline 121.79 & 87.42 & $6 / 19 / 98$ \\
\hline 122.23 & 87.17 & $6 / 19 / 98$ \\
\hline 98.82 & 77.18 & $8 / 25 / 98$ \\
\hline 114.55 & 85.48 & $9 / 16 / 98$ \\
\hline 116.97 & 86.45 & $9 / 16 / 98$ \\
\hline 113.79 & 84.11 & $9 / 16 / 98$ \\
\hline 114.79 & 84.21 & $9 / 16 / 98$ \\
\hline 115.78 & 84.23 & $9 / 16 / 98$ \\
\hline 105.54 & 81.46 & $9 / 18 / 98$ \\
\hline 107.49 & 81.72 & $9 / 18 / 98$ \\
\hline 108.09 & 83.83 & $9 / 18 / 98$ \\
\hline 106.84 & 81.71 & $9 / 18 / 98$ \\
\hline 104.73 & 82.52 & $9 / 18 / 98$ \\
\hline 105.66 & 82.8 & $9 / 18 / 98$ \\
\hline 107.59 & 83.21 & $9 / 18 / 98$ \\
\hline 107.98 & 83.66 & $9 / 18 / 98$ \\
\hline 107.32 & 83.25 & $9 / 18 / 98$ \\
\hline 113.18 & 83.4 & $9 / 16 / 98$ \\
\hline 112.54 & 83.88 & $9 / 16 / 98$ \\
\hline 109.68 & 85.06 & $9 / 23 / 98$ \\
\hline & & \\
\hline
\end{tabular}

